\title{
Active and stable Fe-based catalyst, mechanism, and key role of alkali promoters in ammonia synthesis."
}

Walid Al Maksoud, ${ }^{[a]}$ Rohit K. Rai, ${ }^{[a]}$ Natalia Morlanés, ${ }^{[a]}$ Moussab Harb, ${ }^{[a]}$ Rafia Ahmad, ${ }^{\left[{ }^{[a]}\right.}$ Samy Ould-Chikh, ${ }^{[a]}$ Dalaver Anjum, ${ }^{[b, ~ c] ~ M o h a m e d ~ N . ~ H e d h i l i, ~}{ }^{[b]}$ Bedour E. Al-Sabban, ${ }^{[d]}$ Khalid Albahily, ${ }^{[d]}$ Luigi Cavallo, ${ }^{[a]}$ Jean-Marie Basset *[a]

\section{\#: Dedicated to the memory of Yves Chauvin}

[a] KAUST Catalysis Center and Division of Physical Sciences and Engineering, King Abdullah University of Science and Technology, Thuwal, 23955-6900, Saudi Arabia. Email: jeanmarie.basset@kaust.edu.sa

[b] King Abdullah University of Science and Technology (KAUST), Core Labs, Thuwal, 23955-6900, Saudi Arabia.

[c] Department of Physics, Khalifa University, Abu Dhabi, United Arab Emirates.

[d] SABIC Corporate Research and Development Center at KAUST, Saudi Basic Industries Corporation, Thuwal 23955, Saudi Arabia.

\section{Highlights}

- Cs and K impact drastically the Fe NPs dispersed on N-C support material toward ammonia synthesis.

- A core-shell structure of the Fe NPs obtained with $\mathrm{Fe}^{(0)}$ located on core and surrounded by Cs or K oxides.

- The DFT reveals a geometrical repartition of alkali, leading to a larger number of exposed iron atoms.

- A non-dissociative mechanism proposed by DFT, a stepwise addition of $\mathrm{H}$ on $\mathrm{N}$ leading to $\mathrm{NH}_{3}$.

\footnotetext{
Abstract: Worldwide $\mathrm{NH}_{3}$ production reached 0.18 Gton in 2019 , and $1-2 \%$ of the global $\mathrm{CO}_{2}$ emissions are due to large-scale $\mathrm{NH}_{3}$ synthesis ( 1 billion tons of $\mathrm{CO}_{2}$ / year). A catalyst for ammonia synthesis has been obtained by pyrolysis of iron phthalocyanine (FePc) precursor under $\mathrm{N}_{2}$, followed by impregnation with alkali metals ( $\mathrm{Na}, \mathrm{Li}, \mathrm{K}$, and $\mathrm{Cs}$ ) and $\mathrm{H}_{2}$ treatment. Characterization (XPS, XRD, HR-TEM, ICP-OES, TGA, CHNS analysis, and BET) revealed nano-sized core-shell structures formed during $\mathrm{H}_{2}$ treatment, with $\mathrm{Fe}$ in the core and
} 
promoters (" $\mathrm{Cs}_{2} \mathrm{O}$ " and " $\mathrm{K}_{2} \mathrm{O}$ ") with carbon on the shell. The alkali metals partially inhibit the methanation process of carbon. These Fe NPs were found to be very active and stable catalysts, as compared to the commercial iron-based catalyst KM1 (Haldor-Topsoe). Activities of promoted catalysts follow the order: $\mathrm{K}>\mathrm{Cs}>\mathrm{Na} \sim \mathrm{Li}$, with more than $6 \%$ of $\mathrm{NH}_{3}$ at $400{ }^{\circ} \mathrm{C}$ and $7 \mathrm{MPa}$, and contact time (WHSV) of $12000 \mathrm{ml}^{-1} \cdot \mathrm{g}^{-1}$ with $\mathrm{K}$. The apparent activation energy was found to be $31 \mathrm{~kJ}^{\mathrm{mol}}{ }^{-1}$ and $34 \mathrm{~kJ} . \mathrm{mol}^{-1}$ for $3-\mathrm{K}-\mathrm{FePC}_{700}$ and $10-\mathrm{Cs}-\mathrm{FePC}_{700}$ suggesting the facile activation of $\mathrm{N}_{2}$ on the catalysts surface. DFT-based predicted atomic and electronic structures reveal a similarity in the partial charge distribution on surface Fe species with $\mathrm{K}$ or Cs. Surprisingly the main effect of alkali is related to the geometrical repartition of alkali, leading to a larger number of exposed iron atoms, active sites, in the case of $\mathrm{K}$ than $\mathrm{Cs}$. The alkali (present as metal oxide) leaves at medium coverage of the surface some exposed $\mathrm{Fe}^{(0)}$ for $\mathrm{N}_{2}$ non-dissociative chemisorption (end-on type). The free energy profile demonstrates that the thermodynamic stability of the reaction intermediates for nitrogen reduction reaction (NRR) increases with pressure indicating better feasibility of the reaction at higher pressures.

Keywords: Ammonia synthesis, Iron phthalocyanines, Non-dissociative mechanism, Alkali promoters, Electronic and geometrical effects.

Abbreviations: Iron phthalocyanine: FePc; Supporting Information: SI; X-ray diffraction: XRD; Inductively Coupled Plasma-Optical Emission Spectrometry: ICP-OES; Gas hourly space velocity: WHSV; Mass Spectrometer: MS; X-ray photoelectron spectroscopy: XPS; Temperature-programmed reduction: Temperature-programmed reduction: TPR; Thermogravimetric analysis: TGA; Time on stream: TOS.

\section{Introduction}

Ammonia is one of the largest-volume industrial chemicals synthesized in the world, owing to the use of $\mathrm{NH}_{3}$ as the source of most fertilizers for agriculture, various nitrogen-containing chemicals and materials, nitric acid, clean-burning fuels, refrigerant fluid, and $\mathrm{H}_{2}$ storage and distribution as a significant energy carrier of the future.[1-5] However, the enormous negative environmental impact of the Haber-Bosch process, contributing 1-2 \% of the global $\mathrm{CO}_{2}$ emissions, urgently requires the development of more active and more stable catalysts based on cheap metals for ammonia synthesis.[6-8]

Commonly used catalysts for this process are based on iron, cobalt, or ruthenium with alkali promoters in their formulations.[9-11] The alkali metals are usually reported as "electronic promoters", although important surface structural effects have also been claimed to be due to the addition of these alkali metals. $[12,13]$ The alkali promotion is commonly assumed to proceed via "electron transfer" from the alkali to the Fe or Ru surface.[14-16] As a result, the barrier for 
"nitrogen dissociation" would be decreased. Indeed, some authors claim "nitrogen dissociation" is the rate-limiting step in ammonia synthesis.[10, 17-20] In parallel, all $\mathrm{NH}_{\mathrm{x}}$ species, including adsorbed $\mathrm{NH}_{3}$ molecule, would be destabilized, resulting in more "vacant sites" on the active surface and thus increasing the catalytic activity.[21, 22] [23, 24] Other authors point out that the addition of alkali metals would remove the so-called "retarding" species $\left(\equiv \mathrm{N},=\mathrm{NH},-\mathrm{NH}_{2}\right)$ from the surface. In this theory, the surfaces of Fe catalysts are believed to be covered by the intermediate surface $\mathrm{NH}_{\mathrm{x}}$ species, which are in equilibrium with the produced ammonia and the reactant hydrogen. Highly negative order with respect to $\mathrm{NH}_{3}$ (about -2 reported for most of the iron-based catalysts) indicates that the "retarding species" ( $\equiv \mathrm{N},=\mathrm{NH}$, and $-\mathrm{NH}_{2}$ ) are strongly adsorbed to the surface. In this context, the surface nature of the catalyst might be drastically changed by the addition of alkali, changing the relative concentration of the main surface adsorbed species $\left(-\mathrm{NH}_{3}\right.$, $-\mathrm{NH}_{2},=\mathrm{NH}$, and $\left.\equiv \mathrm{N}\right)$. [25]

Even though dissociated forms of dinitrogen are likely formed on the surface during ammonia synthesis, their role in the mechanism of ammonia synthesis is not proven. A non-dissociative mechanism has been recently proposed in which the adsorbed $\mathrm{N}_{2}$ undergoes systematic hydrogenation to ${ }^{*} \mathrm{HNNH},{ }^{*} \mathrm{NH}-\mathrm{NH}_{3}$, and $\mathrm{NH}_{3(\mathrm{~g})} \cdot[18,26,27]$ The mechanistic hypotheses are based on experimental and DFT calculations, showing that a single Ta atom on silica surface transforms $\mathrm{N}_{2}$ to ammonia by a non-dissociative mechanism. Other examples performed by DFT calculations lead to the same conclusions with $\mathrm{Fe}_{3}$ cluster on the $\theta-\mathrm{Al}_{2} \mathrm{O}_{3}(010)$ surface singleatom catalysis. $[28,29]$

Very efficient and stable catalysts for ammonia synthesis have been recently developed in our laboratory based on the pyrolysis of FePc.[30] The same material was also claimed to be precursors for the reverse reaction of ammonia decomposition to $\mathrm{H}_{2}$ and $\mathrm{N}_{2}$.[31]

In general, the solid-state pyrolysis of metal-organic compounds (e.g., MOFs or phthalocyanines) generates metal NPs confined into carbon porous nanostructures.[32-34] The material resulting from pyrolysis of $\mathrm{FePc}$, which are iron NPs supported on nitrogen-doped carbon composites, exhibit catalytic activities for ammonia synthesis and compare favourably with benchmark industrial iron catalysts (iron doubly promoted catalyst, KM1 from Haldor Topsoe) when combined with alkali metals.[30, 35] The important role of the alkali metal in these systems was illustrated by the fact that in the absence of the alkali metal, the reaction rate was dramatically decreased. $[36,37]$ Thus, we found it exciting to elucidate the real effect of the alkali metal in the recently developed phthalocyanine-based catalysts for ammonia synthesis for Fe-based catalysts.[30]. [38] 


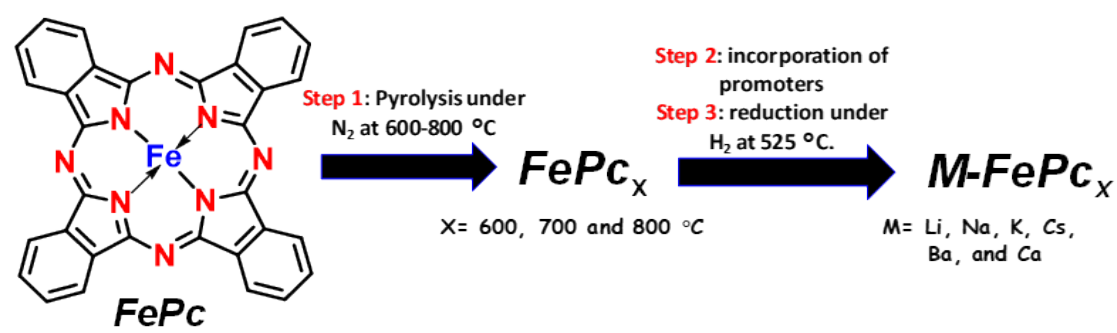

Scheme 1. Schematic illustration for the preparation of promoted FePc catalysts towards ammonia synthesis.

The catalyst was prepared via two steps: firstly, pyrolysis under nitrogen of the FePc precursor at high temperature and secondly, activation/reduction under a hydrogen atmosphere at $525{ }^{\circ} \mathrm{C}$ (Scheme 1). Herein, we decided to elucidate the role of various promoters on the structure of the catalyst. However, we could not do this investigation without elucidating the structural modifications occurring during these two steps (pyrolysis and $\mathrm{H}_{2}$ treatment) of synthesis. The objective was to obtain a structure-activity relationship in a complex system. For that purpose, many techniques were systematically applied. The critical role of the alkali metals (especially $\mathrm{K}$ and Cs) on the ammonia synthesis (localization on the surface and chemical composition) has been clearly identified. Furthermore, using DFT calculations, we predict the structure of the catalysts, particularly after the addition of $\mathrm{K}$ and $\mathrm{Cs}$ and their role in improving the catalytic activity of the catalysts. The final core-shell structures with $\mathrm{Fe}$ in the core and carbon-alkali metal in the shell results in high catalytic activity attributed to the intimate contact of the alkali with the active species, providing at the same time structure stability by preventing the methanation and ensuring the iron dispersion, as well as controlling the exposed active area by the geometric repartition of the alkali species on the catalytic structure.

\section{Experimental Section}

\subsection{Synthesis:}

Several catalysts were studied with the aim of understanding the structural transformations occurring during the 2 steps involved in the preparation of the catalysts derived from phthalocyanine starting materials (pyrolysis under $\mathrm{N}_{2}$ followed by $\mathrm{H}_{2}$ treatment) and the role of the alkali metal in the catalytic performance of FePc catalysts for ammonia synthesis reaction. Experimental procedures are detailed in supporting information (SI).

The iron-based catalysts were prepared by the pyrolysis of FePc. The FePc precursor was introduced onto a crucible and heated $\left(2^{\circ} \mathrm{C} / \mathrm{min}\right)$ under nitrogen flow $(100 \mathrm{ml} / \mathrm{min})$ to different 
temperatures ranging from 600 to $800{ }^{\circ} \mathrm{C}$ and kept for $3 \mathrm{~h}$. After cooling down to room temperature, the materials were passivated under $5 \% \mathrm{O}_{2}$ in $\mathrm{N}_{2}$ for one hour. After pyrolysis, alkali metal ( $\mathrm{Li}, \mathrm{Na}, \mathrm{K}, \mathrm{Cs}$ ) nitrates were incorporated by incipient impregnation using a water-ethanol mixture (2/1 vol. ratio). Before the catalytic test, an activation/reduction step under $\mathrm{H}_{2}$ was carried out at $525{ }^{\circ} \mathrm{C}$ for $6 \mathrm{~h}$. Finally, the samples were kept under an inert atmosphere inside a glove box.

In order to analyze the effect of pyrolysis temperature, several samples were prepared at different pyrolysis temperatures in the range of $600-800{ }^{\circ} \mathrm{C}$. These materials were named $\mathrm{FeP} \mathrm{c}_{\mathbf{x}}$, where $\mathbf{x}$ $\left(600,700\right.$, and $\left.800^{\circ} \mathrm{C}\right)$ indicates the pyrolysis temperature. After pyrolysis, those samples were impregnated in the open air with $10 \%$ wt. $\mathrm{Cs}$ and finally reduced under $\mathrm{H}_{2}$ at $525^{\circ} \mathrm{C}$ for $6 \mathrm{~h}$, before activity measurement. In the particular case of $\mathrm{Cs}$, the catalysts were named $10-\mathrm{Cs}-\mathrm{FePc}_{\mathbf{x}}$.

In order to analyze the effect of the promoters on structure and activity, different alkalis ( $\mathrm{Li}, \mathrm{Na}$, $\mathrm{K}, \mathrm{Cs}$,) were incorporated in the $\mathrm{FePc}$ material obtained after pyrolysis at $700{ }^{\circ} \mathrm{C}$, keeping constant the molar content $0.77 \mathrm{mmol} / \mathrm{g}$ of material after pyrolysis. The samples were named $\mathrm{Y}$, with $\mathrm{Y}\left(\mathrm{Li}, \mathrm{Na}, \mathrm{K}\right.$. Cs) indicates the alkali impregnated on $\mathrm{FePc}_{700}$. For example, for $\mathrm{Li}$ the sample was named Li-FePcx.

\subsection{Catalytic test:}

The catalytic performance to evaluate the activity in ammonia synthesis reaction was studied in a fixed-bed flow reactor using Micro activity units, PID. The catalytic activity for all the catalysts was evaluated at $400{ }^{\circ} \mathrm{C}$ and different pressure in the range 0.1-7 MPa; and the stability of the catalytic performance versus time on stream at $7 \mathrm{MPa}$ and $400{ }^{\circ} \mathrm{C}$. Constant volume of the catalyst $(0.25 \mathrm{~mL}, \sim 200 \mathrm{mg}$ or $0.125 \mathrm{~mL}, \sim 100 \mathrm{mg})$ and reactant mixture flow rate $\left(\mathrm{N}_{2} / \mathrm{H}_{2}, 1 / 3\right.$, $40 \mathrm{~mL} / \mathrm{min}$ ), was used to keep constant gas hourly space velocity (WHSV) of 12000 or $24000 \mathrm{ml}$ $\mathrm{g}^{-1} \mathrm{~h}^{-1}$. Before the catalytic tests, the pretreatment or activation steps were carried out under $\mathrm{H}_{2} / \mathrm{N}_{2}$ (3/1 molar ratio) at $490^{\circ} \mathrm{C}$ for $6 \mathrm{~h}$. In order to avoid any contact with the open air, the catalyst was loaded into the reactor inside the glovebox, where the catalysts are kept after the activation treatment under hydrogen. This protocol was developed to take into consideration for rate measurements the weight loss that occurs during this reduction treatment (analyzed and described below). This provided accurate ammonia synthesis rates expressed in $\mu \mathrm{mol} \mathrm{NH}_{3}$ $\mathrm{h}^{-1} \mathrm{~g}_{\mathrm{cat}}{ }^{-1}$ as well as ammonia \% in the reactor outlet. The $\mathrm{NH}_{3}$ produced in each experiment was monitored quantitatively by an online connected Mass-Vac Spectrometer (detection limit less than $5 \mathrm{ppb})$. See more details in SI. 


\subsection{Computational Methodology:}

For Fe support simulation, we considered the $(4 \times 4)$ cubic periodic slab model containing $5 \mathrm{Fe}$ layers or 160 atoms from the optimized bulk cell dimensions of the body-centered cubic (bcc) crystal structure by cleaving the original bulk through a matrix transformation along with the (110) Miller index crystallographic plane to obtain the required surface. We set a relatively large vacuum width in the perpendicular direction to the surface to avoid any fictitious interaction between the neighboring slabs along this direction. We have chosen this number of Fe layers after performing benchmark convergence tests on the evolution of the electronic structure features (such as cohesive energy and Fermi level position) as a function of the slab thickness.

For simulations of Cs- and K- containing Fe structures, $\left(\mathrm{Cs}_{2} \mathrm{O}\right) \mathrm{n}$ and $\left(\mathrm{K}_{2} \mathrm{O}\right) \mathrm{n}$ clusters $(\mathrm{n}=2,3$, and 4) with $\mathrm{O}$ : Cs and $\mathrm{O}: \mathrm{K}$ ratios of 0.5 were deposited on top of $\mathrm{Fe}(110)$ surface to mimic the obtained experimental samples by maintaining +1 oxidation states for $\mathrm{Cs}$ and $\mathrm{K}$ species. Several possible key atomic structures for the clusters, particularly for $n=4$, revealing aggregated (symmetric or distorted) and dispersed geometry types, were explored in order to find the most favorable situations of $\mathrm{Cs}$ and $\mathrm{K}$ species on top of $\mathrm{Fe}(110)$ surface. For $\mathrm{n}=3$ and 2, the lowestenergy structures were found starting successively from the most stable configurations obtained for $\mathrm{n}=4$. They were obtained by removing, respectively, one and two $\mathrm{Cs}_{2} \mathrm{O}$ (or $\mathrm{K}_{2} \mathrm{O}$ ) species from different structural locations on the Fe surface to ensure the convergence of the minimum electronic energy.

All generated geometries were optimized by means of the periodic density functional theory (DFT) with the projector augmented plane wave (PAW) method [39] as implemented in the VASP simulation software.[40-43] The Perdew-Burke-Ernzerhof (PBE) exchange-correlation functional [44] together with a kinetic energy cutoff of $400 \mathrm{eV}$ for electron wave basis functions, and a $3 \times 3$ $x 1$ Monkhorst-Pack $k$-point grid for sampling the first Brillouin zone were used.[45] The valence electrons taken into account explicitly in the PAW potentials are $3 d^{7} 4 s^{1}$ for Fe, $5 s^{2} 5 p^{6} 6 s^{1}$ for Cs, $3 s^{2} 3 p^{6} 4 s^{1}$ for $K$, and $2 s^{2} 2 p^{4}$ for $O$. The spatial positions of the various species were fully relaxed and the structures were considered well converged when the three principal residual Hellmann-Feynman forces on each species were near $0.01 \mathrm{eV} . \AA^{-1}$, the atomic displacements were near $10^{-4} \AA$, and the convergence criterion for the self-consistent field (SCF) cycles for energy change was near $0.01 \mathrm{meV}$. Thermodynamic calculations were performed to estimate the most stable catalyst structures by mimicking the experimental setup used for preparation. The considered reaction used $\mathrm{H}_{2}$ in the gas phase as a hydrogen source as follows:

$$
\mathrm{Fe}(110)-\left(\mathrm{A}_{2} \mathrm{O}\right)_{n}+n \mathrm{H}_{2} \rightarrow \mathrm{Fe}(110)-\mathrm{A}_{2 n}+n \mathrm{H}_{2} \mathrm{O}(\mathrm{A}=\mathrm{Cs} \text { or } \mathrm{K})(1) \text {. }
$$


The formation of energy was computed using this expression: $E_{\text {form }}(1)=E\left[F e(110)-A_{2 n}\right]-$ $\mathrm{E}\left[\mathrm{Fe}(110)-\left(\mathrm{A}_{2} \mathrm{O}_{\mathrm{n}}\right]+\mathrm{n} . \mathrm{E}\left[\mathrm{H}_{2} \mathrm{O}\right]-\mathrm{n} \cdot \mathrm{E}\left[\mathrm{H}_{2}\right]+\mathrm{n} \cdot \Delta \mu_{\mathrm{H} 2 \mathrm{O}}-2 \mathrm{n} . \Delta \mu_{\mathrm{H}}\right.$

The electronic energies of $\mathrm{Fe}(110)-\left(\mathrm{A}_{2} \mathrm{O}\right)_{n}$ and $\mathrm{Fe}(110)-\mathrm{A}_{2 n}$ materials in their lowest-energy configuration were described by $\mathrm{E}\left[\mathrm{Fe}(110)-\left(\mathrm{A}_{2} \mathrm{O}\right)_{n}\right]$ and $\mathrm{E}\left[\mathrm{Fe}(110)-\mathrm{A}_{2 n}\right] . \mathrm{E}\left[\mathrm{H}_{2} \mathrm{O}\right]$ and $\mathrm{E}\left[\mathrm{H}_{2}\right]$ represent the electronic energies of $\mathrm{H}_{2} \mathrm{O}$ and $\mathrm{H}_{2}$ molecules in gas phase. The thermal part of hydrogen or water chemical potential $\left(\Delta \mu_{\mathrm{H}}\right)$ or $\left(\Delta \mu_{\mathrm{H}_{2} \mathrm{O}}\right)$ depends on temperature $(\mathrm{T})$ and partial pressure $(p)$ through the enthalpy $(h)$ and entropy (s) corrections. The zero-point vibrational energy as a function of $T$ and $p$ was included into the thermal corrections. This was computed through DMol software [46] within the PBE functional and the double numerical polarization (DNP) basis set. ${ }^{[47]} \mathrm{Here}, \Delta \mu_{H}$ was varied as a function of $p\left(H_{2}\right)$ under the experimental condition $T=400$ ${ }^{\circ} \mathrm{C}$. $\Delta \mu_{\mathrm{H}_{2} \mathrm{O}}$ was fixed at the same temperature and at atmospheric pressure. For $\mathrm{Fe}(110)-\left(\mathrm{A}_{2} \mathrm{O}\right)_{n}$, the reference formation energy was set to $0 \mathrm{eV}$ to compare relatively the stability of $\mathrm{Fe}(110)-\mathrm{A}_{2 n}$ catalysts to the pristine ones. This methodology has demonstrated its capability of matching the experimental observations while studying the thermodynamics of doped or defective materials used in catalysis and photoelectrochemitry. [48-50]

Bader charge analysis was performed on the most stable structures to give deep insight into any possible electron transfer between the deposited alkali $\mathrm{Cs}$ and $\mathrm{K}$ elements and the Fe support. This analysis was also helpful in identifying the species involved in this process as well as the amount of transferred electrons.

\section{Results and Discussion}

\subsection{Structural Characterization:}

\subsubsection{Pyrolysis temperature}

Several catalysts were prepared at different pyrolysis temperatures in the range of $600-800{ }^{\circ} \mathrm{C}$ (First step, Scheme 1). Structural transformation occurring during the pyrolysis has been investigated by TGA, XRD, XPS, elemental analysis CHNS, ICP-OES, $\mathrm{N}_{2}$ physisorption. Results are detailed in the SI (Figs. S2-S5 and Table S1). During the pyrolysis step, the decomposition of the organic ligand provokes changes in the structure and composition ( $\mathrm{Fe}, \mathrm{C}$, and $\mathrm{N}$ ) of the material. Carbon and nitrogen contents decrease, and a simultaneous iron content increase is observed with increasing pyrolysis temperature. After the pyrolysis step of FePc at different temperatures $\left(600-800^{\circ} \mathrm{C}\right), 10 \%$ wt. of $\mathrm{Cs}$ was introduced $(0.077 \mathrm{~mol} \% / \mathrm{g})$. The samples were activated under pure $\mathrm{H}_{2}$ at $525{ }^{\circ} \mathrm{C}$ for $6 \mathrm{~h}$ (Scheme 1) to obtain the catalysts (10-Cs-FePc$c_{600}, 10-$ 
Cs- $\mathrm{FePc}_{700}$, and 10-Cs- $\mathrm{FePC}_{800}$ ) that were kept in a glove box. The activation process under the hydrogen atmosphere is required to form the catalytically active $\alpha$-Fe species. [51, 52]

Reducibility of the iron species and changes in the structure and composition occurring during the activation has been investigated by TPR, TGA, XRD, ICP-OES, CHNS, and BET (Figs. S6-S7 and Table S2). Interestingly, the reduction of iron occurs together with incomplete hydrogenation of the carbon support to form methane.[53-55] This methanation process of the carbon support results in a considerable weight loss of the sample, corresponding decrease of the carbon content (55-60 wt. \%) and an increase in the iron content while providing mesoporosity to the final material (pore size $>2 \mathrm{~nm}$ ). A significant loss of nitrogen content is also observed. The XRD patterns of $10-\mathrm{Cs}-\mathrm{FePc}_{600}$ and $10-\mathrm{Cs}-\mathrm{FePc}_{700}$ catalysts (Fig. S7) show that the materials undergo various phase transformations during the $\mathrm{H}_{2}$ treatment $525^{\circ} \mathrm{C}$, to form mostly $\alpha-\mathrm{Fe}$ as evidenced by the reflections of $\alpha-\mathrm{Fe}, 110,200$, and 211 , at $44.7^{\circ}, 65.0^{\circ}$, and $82.3^{\circ}(2 \theta)$, respectively.

The morphology of the catalysts after activation under $\mathrm{H}_{2}$ at $525^{\circ} \mathrm{C}$ for $6 \mathrm{~h}$ was imaged by highangle annular dark-field scanning transmission electron microscopy (HAADF-STEM). Representative TEM images, their corresponding elemental mapping ( $\mathrm{Fe}, \mathrm{Cs}, \mathrm{C}$, and $\mathrm{O}$ ), and the particle size distribution for $10-\mathrm{Cs}-\mathrm{FePc}_{600}, 10-\mathrm{Cs}-\mathrm{FePC}_{700}$, and $10-\mathrm{Cs}-\mathrm{FePc}_{800}$ are illustrated in Fig. 1 and Fig. S9 A. The TEM images show a population of spherical iron nanoparticles supported homogeneously onto the nitrogen-doped carbon with a fainter contrast corresponding to a cesium layer decorating the surface of the iron nanoparticles.

The pyrolysis temperature strongly affects the particle size distribution of the metallic iron nanoparticles, with an increase in the average particle size from 12 to $70 \mathrm{~nm}$, when increasing the pyrolysis temperature at $600^{\circ} \mathrm{C}, 700^{\circ} \mathrm{C}$, or $800^{\circ} \mathrm{C}$ (Fig. S9 A).

Interestingly, the elemental map of the catalysts confirmed the formation of a core-shell structure, with the Fe located in the core, whereas the $\mathrm{Cs}, \mathrm{C}$, and O were distributed on the shell (Fig. 1 B, D, and F). More specifically, the line scan analysis across the NPs (Fig. 1, D, and G) explored under Argon inert atmosphere clearly shows that $\mathrm{Cs}$ and $\mathrm{O}$ atoms are forming an amorphous "Cs $\mathrm{s}_{\mathrm{x}} \mathrm{O}$ " phase dispersed around the Fe NPs. Furthermore, with HR-TEM imaging (Fig. $1 \mathrm{H}$ ), we can see clearly that the carbon and alkali metals are forming a multilayer structure in the shell without a possible distinction between $\mathrm{Cs}$ and $\mathrm{C}$. Moreover, at the interface of iron and carbon, there is a possibility to have an iron-carbide; nevertheless, it is difficult to identify by XPS or XRD. Note also that the modeling studies regarding the possible reduction of the " $\mathrm{Cs}_{2} \mathrm{O}$ " phase indicate that $\mathrm{Cs}^{(+1)}$ cannot be reduced even at elevated temperatures under $\mathrm{H}_{2}$ (see later Fig. 8), 
consistent with the XPS analysis. This clearly means that Cs species remains as a cesium oxide within the final material.

The formation of these core-shell structures is claimed to be responsible for the improvement of the activity. Because of this intimate contact between $\mathrm{Cs}$ and Fe, a strong metal-promoter interaction is likely to occur and might be the origin of the enhanced catalytic activity. This kind of carbon-shell structure around iron nanoparticles has been previously reported for similar catalysts prepared by pyrolysis of different organometallic compounds, including iron porphyrin precursor. $[32,56]$

The surface chemical composition and oxidation state were investigated using XPS of the 10-Cs$\mathrm{FePc}_{600}, 10-\mathrm{Cs}-\mathrm{FePC}_{700}$, and $10-\mathrm{Cs}-\mathrm{FePC}_{800}$ after activation under $\mathrm{H}_{2}$ at $525^{\circ} \mathrm{C}$ for $6 \mathrm{~h}$. Fig. S8 shows that the XPS spectra of the Cs 3d levels exhibit two sharp peaks at 725.1 and $735.2 \mathrm{eV}$, consistent with $\mathrm{Cs}^{+1}$ oxidation state. [57] While the $\mathrm{Fe} 2 \mathrm{p}_{3 / 2}$ peaks corresponding to $\mathrm{Fe}^{(0)}$, for the 10-Cs-FePc $\mathrm{C}_{600}, 10-\mathrm{Cs}-\mathrm{FePc}_{700}$, and $10-\mathrm{Cs}-\mathrm{FePc}_{800}$ appeared at $\sim 706.6 \mathrm{eV}$ showing lower intensity (shown in the zoomed area) as compared to the Cs peaks. This corroborates that Cs is covering or is wrapping the iron nanoparticles in agreement with the core-shell structure observed by HRTEM and HAADF-STEM elemental mapping (Fig. 1). A less intense peak at $710.8 \mathrm{eV}$ also appeared in the spectra of $10-\mathrm{Cs}-\mathrm{FePc}_{600}$ and $10-\mathrm{Cs}-\mathrm{FePc}_{700}$ catalysts, which correspond to iron oxide, whereas in $10-\mathrm{Cs}-\mathrm{FePC}_{800}$ catalyst, this peak is not detected. The presence of iron oxide may be due to the experimental pollution of the samples by $\mathrm{O}_{2}$ present in the introduction chamber, as discussed later.[58] 


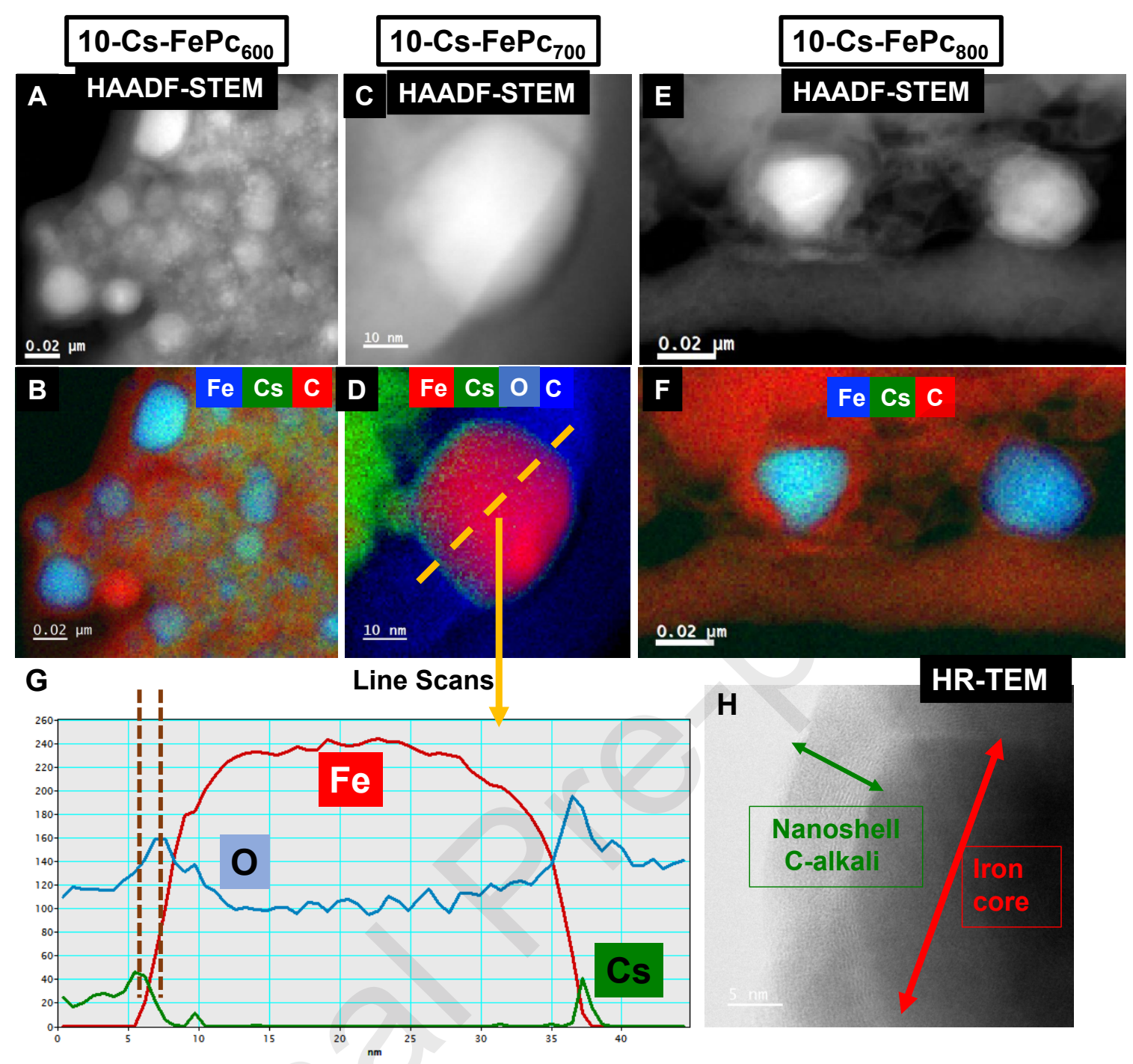

Fig. 1. HAADF-STEM images for the catalysts after the treatment under $\mathrm{H}_{2}$ at $525{ }^{\circ} \mathrm{C}$ for 6

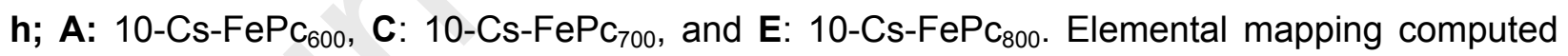
from spectral imaging data acquired by STEM-EELS; B: 10-Cs-FePc 600 Fe (blue), C (red), and Cs (green); D 10-Cs-FePc ${ }_{700}$ Fe (red), C (dark blue ), Cs (green) and O (light blue); F: 10-Cs$\mathrm{FePc}_{800}, \mathrm{Fe}$ (blue), C (red), and Cs (green); G: line scan across one of the iron NPs; Fe (red), C (dark blue ), Cs (green) and O (light blue), and H: HR-TEM picture for $10-C s-F^{-P C} C_{700}$ catalyst.

\subsubsection{Various alkali metals}

Furthermore, to elucidate the role of the alkali promoters, several catalysts were prepared by using different alkali metals ( $\mathrm{Li}, \mathrm{Na}, \mathrm{K}$, and $\mathrm{Cs})$, while keeping the same molar loading (0.77 $\mathrm{mmol} / \mathrm{gram})$. The promoters were introduced after the pyrolysis under $\mathrm{N}_{2}$ at $700{ }^{\circ} \mathrm{C}$, and the catalysts were then activated under $\mathrm{H}_{2}$ at $525{ }^{\circ} \mathrm{C}$ for $6 \mathrm{~h}$, and finally, kept under an inert 
atmosphere, to be analyzed by ICP-OES, CHNS analysis, $\mathrm{N}_{2}$-Physisorption for BET analysis, XPS, and HR-TEM analysis.

Regarding the composition detailed in Table 1, the addition of alkali promoter drastically inhibits the methanation process occurring during the hydrogen treatment. This prevents the sample from the intense weight loss that results in a decrease of the $\mathrm{C}$ content and an increase of the $\mathrm{Fe}$ content. In the absence of promoter, the amount of $\mathrm{C}$ remaining after the reduction process is very low ( $8 \% w t$.), and the amount of Fe is very high (80\%wt.). In the presence of promoter, the amount of remaining $\mathrm{C}$ is around $32 \%$ wt. and the amount of $\mathrm{Fe}$ is around $35 \%$ wt. for $10-\mathrm{Cs}-$ FePc $_{700}$ (Table 1).

Therefore, the introduction of alkali metal partially prevents the carbon from interacting with active hydrogen. [54] Note that the weight loss observed during the $\mathrm{H}_{2}$ treatment leads to a 2 to 3 fold increase in the promoter content compared to the original content (Table 1). Notably, after the catalytic reaction, there were no significant changes observed in the alkali content in the catalysts (Table 1), suggesting that during the catalytic reaction, the alkali oxide $\left(\mathrm{Cs}_{2} \mathrm{O}\right.$ and $\left.\mathrm{K}_{2} \mathrm{O}\right)$ remains stable. ${ }^{26}$ At the same time, a slightly smaller loss of $\mathrm{N}$ is also observed in the promoted samples (1-2\%), compared to the non-promoted one (0.5\%) (Table 1). It has been claimed that the presence of nitrogen in the catalyst could enhance the catalytic properties of the catalysts. [59, 60] All these values indicate that the alkali metal prevents the loss of carbon, which is becoming the support of Fe NPs. The alkali-promoted samples are mesoporous structures developing a BET surface area range of 80 to $280 \mathrm{~m}^{2} / \mathrm{g}$. In contrast, the non-promoted sample had such a low surface area that we couldn't measure it. Indeed, the particle size distribution in $\mathrm{FePc}_{700}$ without promoter is higher than $80 \mathrm{~nm}$. [61, 62] The increase in the particle size observed for the nonpromoted sample is related to the enormous loss of carbon support (85\% weight loss), leading to a final $80 \%$ wt. of Fe content (Table 1).

Table 1. Effect of alkali promoter: Composition and textural properties of the catalysts after the $\mathrm{H}_{2}$ treatment at $525^{\circ} \mathrm{C} 6 \mathrm{~h}$.

\begin{tabular}{ccccccc}
\hline Samples & Fe wt. (\%) & ${ }^{[a]}$ Alkali wt. (\%) & Alkali/Fe & C wt. (\%) & ${ }^{[b]} \mathrm{N}$ wt. (\%) & BET (m²/g) \\
\hline FePc $_{700}$ & 80 & 0 & 0 & 8 & 0.5 & ND \\
\hline $10-\mathrm{Cs}-\mathrm{FePC}_{700}$ & 30 & $23[22.5]$ & 0.32 & 32 & 1 & 86 \\
\hline $3-\mathrm{K}-F e P c_{700}$ & 43 & $10[9.7]$ & 0.33 & 31 & 1.5 & 147 \\
\hline $1.8-\mathrm{Na}-\mathrm{FePC}_{700}$ & 60 & 6 & 0.24 & 22 & 2 & 68 \\
\hline
\end{tabular}


$0.5-\mathrm{Li}_{-} \mathrm{FePC}_{700}$

51

4

4

[a]: the samples were analyzed after a hydrogen treatment at $525^{\circ} \mathrm{C}$, and in the bracket[], the samples were analyzed after the catalytic reaction. ${ }^{[b]}: \mathrm{O}$ and $\mathrm{H}$ are the remaining elements.

The morphology of $10-\mathrm{Cs}-\mathrm{FePC}_{700}, 1.8-\mathrm{Na}-\mathrm{FePC}_{700}$, and 3-K-FePc $\mathrm{C}_{700}$ catalysts after $\mathrm{H}_{2}$ treatment at $525{ }^{\circ} \mathrm{C}$ were studied by HAADF-STEM images (Fig. 2). The Fe NPs are dispersed onto the nitrogen-doped carbon support material, as observed in Fig. 1, forming the core-shell structure previously described. The alkali species, $\mathrm{Cs}, \mathrm{K}$, and $\mathrm{Na}$, are also distributed over the whole carbon-nitrogen matrix. The iron is located in the core region, whereas the $\mathrm{Cs}, \mathrm{K}$, and $\mathrm{Na}$ are distributed on the shell mixed with the $\mathrm{C}$ and $\mathrm{O}$.

The particle size distribution of $10-\mathrm{Cs}-\mathrm{FePC}_{700}, 3-\mathrm{K}-\mathrm{FePC}_{700}$, and $1.8-\mathrm{Na}-\mathrm{FePC}_{700}$ catalysts are indicated in Fig. S9, B. The 3-K-FePc $\mathrm{C}_{700}$ and $10-\mathrm{Cs}-\mathrm{FePC}_{700}$ give the smaller average particle size (11 and $15 \mathrm{~nm}$, respectively), while larger particles of $\mathrm{Fe}$ are observed for 1.8-Na-FePc $\mathrm{C}_{700}(\sim 32.3$ $\mathrm{nm}$ ). The catalyst promoted with all alkali metals (not only Cs) prevents the loss of carbon by inhibiting the methanation, and the iron species remains highly dispersed. It is corroborated that the addition of alkali metals is an important structural promoter to prevent the sintering of the iron nanoparticles.

The XPS analysis for the $\mathrm{FePc}_{700}, 10-\mathrm{Cs}-\mathrm{FePC}_{700}, 3-\mathrm{K}-\mathrm{FePc}_{700}$, and 1.8-Na-FePc $\mathrm{C}_{700}$ catalysts was also investigated. (Fig. S10). Surprisingly, for $\mathrm{FePC}_{700}$ without a promoter, after reduction under $\mathrm{H}_{2}$ at $525^{\circ} \mathrm{C}$, the peak around $710.6 \mathrm{eV}$ (iron oxide) is much more intense as compared to the peak of $\mathrm{Fe}^{(0)}$ at $706.6 \mathrm{eV}$. In contrast, in the case of $10-\mathrm{Cs}-\mathrm{FePc}_{700}, 3-\mathrm{K}-\mathrm{FePC}_{700}$, and $1.8-\mathrm{Na}-$ $\mathrm{FePC}_{700}$, under identical activation condition, the XPS shows the presence of a sharp peak of $\mathrm{Fe}^{(0)}$ at $706.6 \mathrm{eV}$ and a much smaller intensity peak of iron oxide at $710.2 \mathrm{eV}$. It can be concluded that the introduction of promoters ( $\mathrm{Na}, \mathrm{K}$, and $\mathrm{Cs}$ ) might be beneficial to reduce iron, as also confirmed by the TPR experiment (Fig. S11). [57, 63, 64] [52] Regarding the oxidation state, several experiments corroborated a very small amount of iron oxide on $10-\mathrm{Cs}-\mathrm{FePc}_{700}, 3-\mathrm{K}-\mathrm{FePc}_{700}$, and 1.8-Na-FePC $\mathrm{C}_{700}$ catalysts were due to a trace of oxygen impurities in the introduction chamber. To confirm this observation, further XPS experiments were performed and confirmed the absence of this peak (For the details, see SI Figs. S12-S13). 


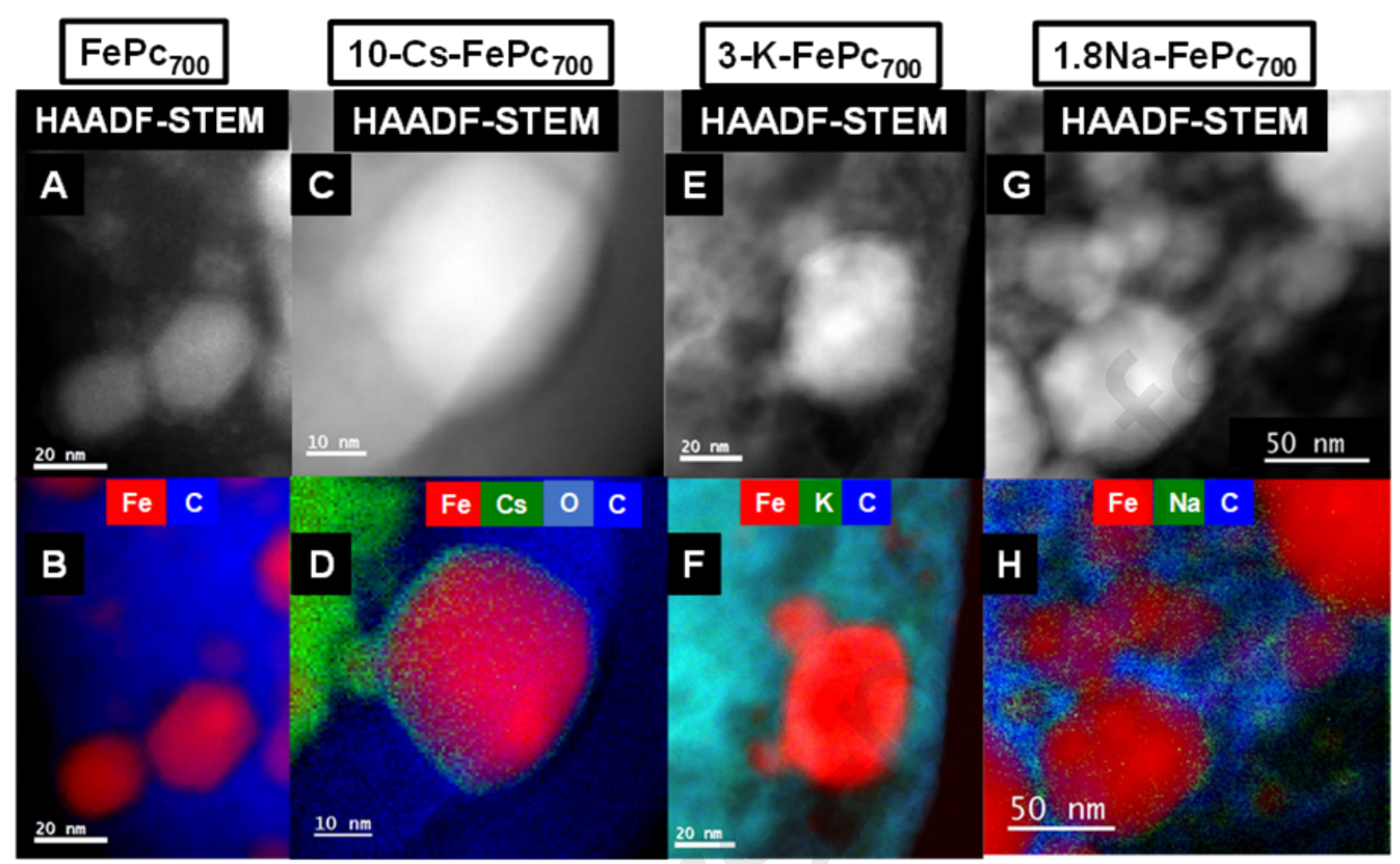

Fig. 2. Representative HAADF-STEM images for $\mathrm{FePC}_{700}$ without promoter, 10-Cs-FePc $\mathrm{C}_{700}$, 3$\mathrm{K}-\mathrm{FePC}_{700}$, and 1.8-Na-FePc $\mathrm{C}_{700}$ catalysts (After the treatment under $\mathrm{H}_{2}$ at $525^{\circ} \mathrm{C}$ for $6 \mathrm{~h}$ ), and the correspondent elemental mapping: $\mathrm{Fe}$ (red), Carbon (blue), $\mathrm{Cs}, \mathrm{K}$ or $\mathrm{Na}$ (green). $\mathbf{A}$ and $\mathbf{B}$ : for $\mathrm{FePC}_{700}$ without a promoter, $\mathbf{C}$ and $\mathbf{D}$ : for $10-\mathrm{Cs}-\mathrm{FePC}_{700}$, $\mathbf{E}$ and $\mathbf{F}$ : for $3-\mathrm{K}-\mathrm{FePC}_{700}$, and $\mathbf{G}$ and $\mathbf{H}$ : for $1.8-\mathrm{Na}-\mathrm{FePC}_{700}$.

Furthermore, the surface oxidation state was corroborated by the extraction of the Fe branching ratio $\left(L_{3} / L_{2}\right)$ from a spectrum imaging dataset acquired by STEM -EELS.[65] The computed results (Fig. 3) clearly showed about $2 \mathrm{~nm}$ thick shell region around the NPs that had a higher branching ratio than the rest of the nanoparticle. [66] This is indicative of a higher valence state for Fe atom located on the surface, which is consistent with the DFT calculations, described later. 

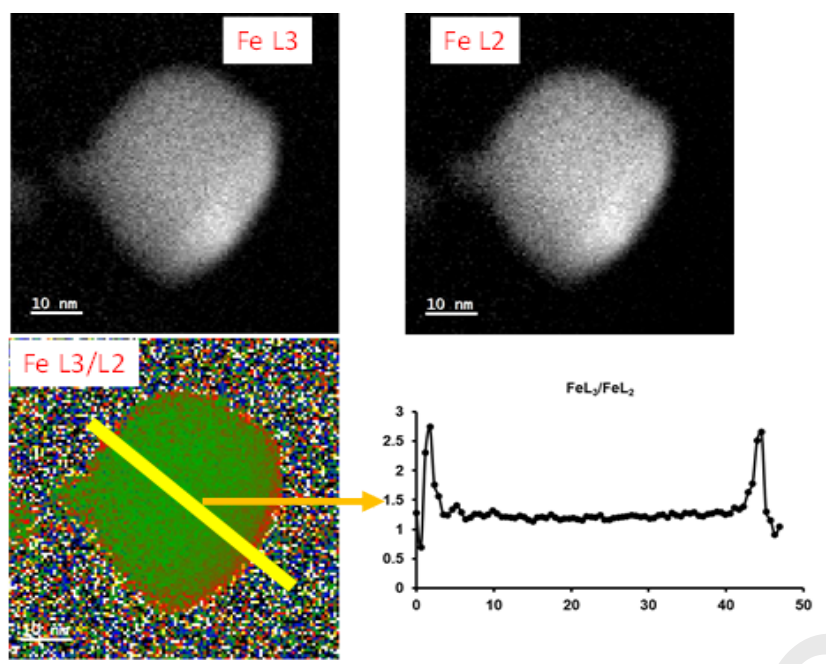

Fig. 3. Line-Scan Profile of the Fe branching ratio $\left(\mathrm{L}_{3} / \mathrm{L}_{2}\right.$ signals ratio for $10-\mathrm{Cs}-\mathrm{FePc}_{700}$ catalyst (After activation under $\mathrm{H}_{2}$ at $525^{\circ} \mathrm{C}$ for $6 \mathrm{~h}$ ).

\subsubsection{Differents amount of promoters (Cs or K)}

Different cesium and potassium loadings were further investigated to find the optimum alkali loadings following the same protocol as described before. Experimental details and characterizations of the samples studied given in the SI (Figs. S14-S17 and Tables S3-S4). The analysis of the effect of the alkali promoter loadings further corroborates the role of the alkali addition in the inhibition of the methanation of the support, preventing the sintering of the nanoparticles and keeping the metal phase dispersion, as previously described. This structural feature is essential for the stability of the structure and the activity.

\subsection{Catalytic performance}

\subsubsection{Effect of pyrolysis}

The catalysts prepared at different pyrolysis temperatures were evaluated for ammonia synthesis reaction with a space velocity WHSV $12.000 \mathrm{ml} \mathrm{g}^{-1} \mathrm{~h}^{-1}$ and compared to iron Benchmark catalyst (Iron doubly promoted catalyst) Haldor-Topsoe catalyst. [17, 35, 67-69]

Fig. $4 \mathrm{~A}$ reveals the ammonia synthesis rates and the ammonia concentration in the reactor outlet at different pressures $(0.1-7 \mathrm{MPa})$ at $400{ }^{\circ} \mathrm{C}$. The rates are 32117,27783 and $18755 \mu \mathrm{mol} \mathrm{NH}_{3}$ $\mathrm{h}^{-1} \mathrm{~g}_{\text {cat. }}{ }^{-1}$, for respectively $10-\mathrm{Cs}-\mathrm{FePc}_{600}, 10-\mathrm{Cs}-\mathrm{FePc}_{700}$ and $10-\mathrm{Cs}-\mathrm{FePc}_{800}$. This rate is 2 to $3-$ fold higher as compared to the commercial benchmark iron-based catalyst (Fig. 4 A). 
Interestingly, the activity for the catalysts is decreasing with the increase of the pyrolysis temperature, while the iron NPs size is increasing $(12,15$, and $70 \mathrm{~nm})$. Nevertheless, the variation of activity with particle size is not spectacular, so we are inclined to neglect this effect of particle size on activity (Table S5). [70]

The stability test of the catalysts was also evaluated. There is no observed decline in activity with TOS for more than $24 \mathrm{~h}$ (Fig. 4 B). It is essential to highlight that no methane is detected during the catalytic reaction in the reactor outlet during the ammonia synthesis conditions $\left(400{ }^{\circ} \mathrm{C}\right.$ and up to $7 \mathrm{MPa}$ ). This is in full agreement with the high stability of the catalysts.

\subsubsection{Effect of different alkalis}

Moreover, the catalytic performance of the catalysts prepared with various alkali metals was also investigated. The $\mathrm{NH}_{3}$ synthesis rates and the $\mathrm{NH}_{3}$ concentration at different pressures (0.1-7 $\mathrm{MPa}$ ) at $400{ }^{\circ} \mathrm{C}$ are shown in Fig. $4 \mathrm{C}$ and D. The most interesting result is the significant improvement in the catalytic performance observed in the samples with alkali metals, with respect to the sample prepared without promoters. The best performances are observed for the catalyst promoted with $\mathrm{K}$, and $\mathrm{Cs}$, with the highest rates $\sim 31.000$ and $\sim 28.000 \mu \mathrm{mol} \mathrm{NH} \cdot \mathrm{h}^{-1} \mathrm{~g}_{\mathrm{cat}}{ }^{-1}$, and ammonia concentration in the reactor outlet, $6 \%$, and $5.4 \%$, for $3-\mathrm{K}-\mathrm{FePc}_{700}$ and $10-\mathrm{Cs}-\mathrm{FePC}_{700}$ respectively (Fig. 4 C).

A stability test was performed at $400{ }^{\circ} \mathrm{C}$ and $7 \mathrm{MPa}$ for the $3-\mathrm{K}-\mathrm{FePC}_{700}, 10-\mathrm{Cs}-\mathrm{FePC}_{700}, 1.8-\mathrm{Na}-$ $\mathrm{FePC}_{700}$ and 0.5-Li-FePc $\mathrm{C}_{700}$ catalysts. As shown in Fig. 4 D, there is no detectable decline in the activity for $24 \mathrm{~h}$. Notably, the best catalysts $\left(10-\mathrm{Cs}-\mathrm{FePc}_{700}\right.$ and $\left.3-\mathrm{K}-\mathrm{FePc}_{700}\right)$ were also tested up to $72 \mathrm{~h}$, without any decline activity (Fig. S18). 
A
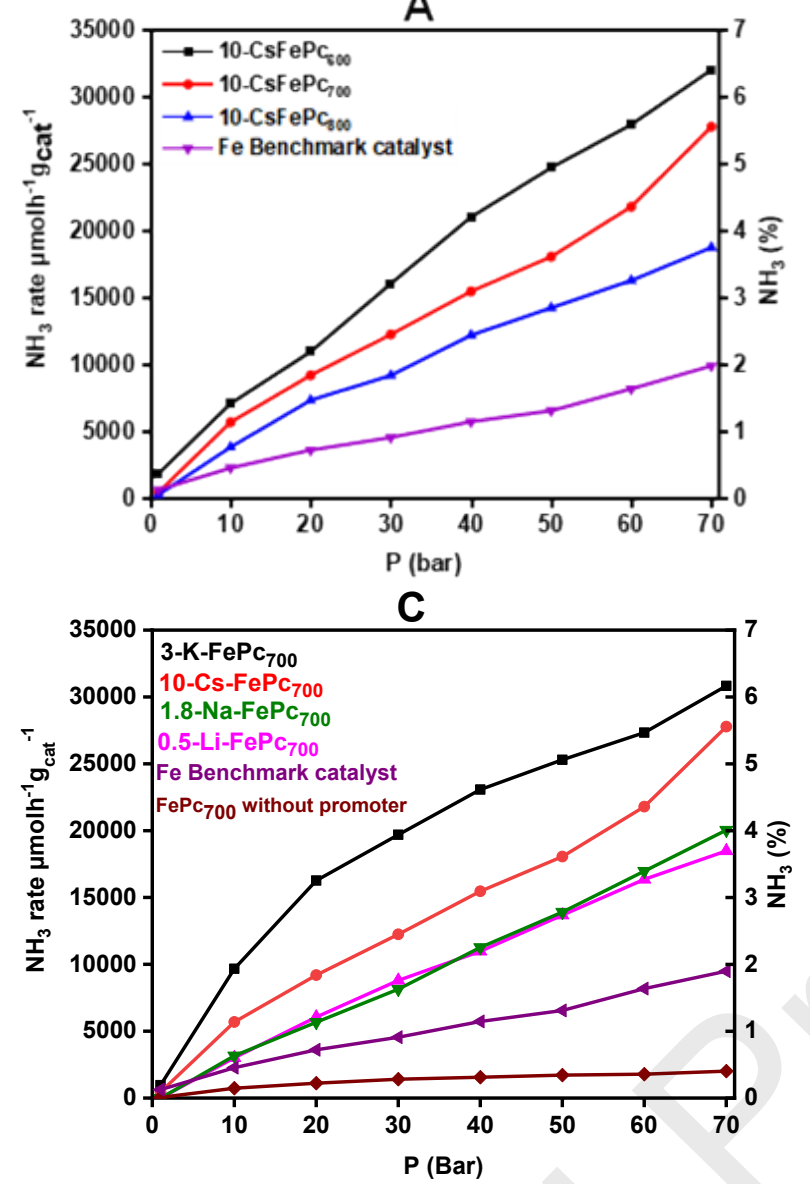
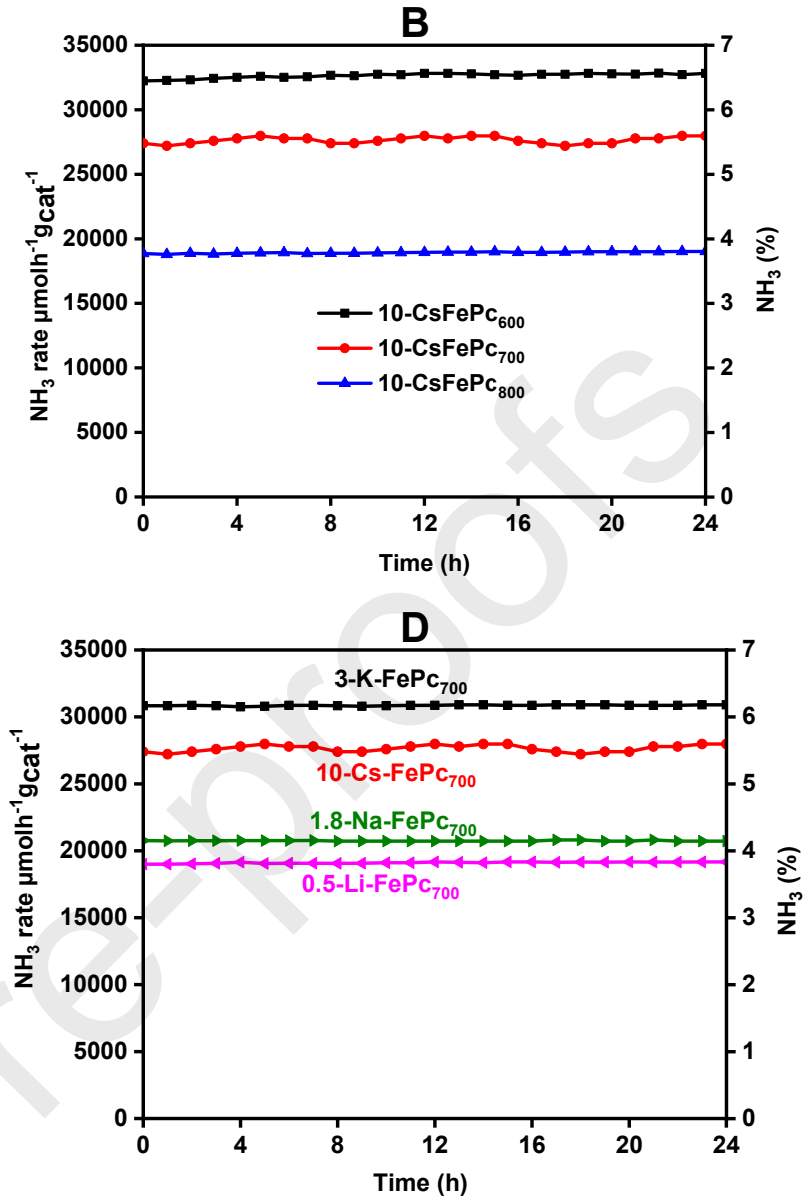

Fig. 4. The catalytic activity of the FePc derived catalysts for the ammonia synthesis. A and B different pyrolysis temperatures $\left(600,700\right.$, and $\left.800^{\circ} \mathrm{C}\right), \mathbf{C}$, and D with different alkali metals. A and $\mathrm{C}$ : $\mathrm{NH}_{3}$ synthesis rate expressed in $\mu \mathrm{mol} \mathrm{NH}_{3} \mathrm{~h}^{-1} \mathrm{~g}_{\mathrm{cat}}{ }^{-1}$ at different pressures (0.1-7 MPa) at $400{ }^{\circ} \mathrm{C}$ (left) and $\mathrm{NH}_{3} \%$ in reactor outlet (right). B and D: Time dependence of the catalytic

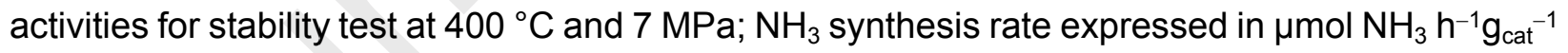
(left) and $\mathrm{NH}_{3} \%$ in reactor outlet (right). Reaction conditions: $200 \mathrm{mg}$ catalyst, flow rate $40 \mathrm{ml}$ $\min ^{-1}, \mathrm{~N}_{2}: \mathrm{H}_{2}=1: 3$, WHSV $12000 \mathrm{ml} \mathrm{g}^{-1} \mathrm{~h}^{-1}$. No methane was detected during the catalytic reaction at $400{ }^{\circ} \mathrm{C}$ and $90.1-7 \mathrm{MPa}$ ); the limit of detection with the Mass-vac spectrometer is less than 5 ppb.

\subsubsection{Effect of promoters loading}

The catalytic performance of the catalysts prepared with different $\mathrm{Cs}$ and $\mathrm{K}$ loading was also investigated (Fig. 5 and Fig. S20-A). We have observed that the effect Cs loading is more pronounced as compared to $\mathrm{K}$ loading. As shown in Fig. 5, the activity is the highest for the 
highest amount of Cs loading, especially when the rate is given per mol of iron, considering the Fe content. This is a spectacular effect of the alkali on the activity. This is particularly true by comparison with the sample without promotor Fig. 5. [71]

A stability test was also performed at $400{ }^{\circ} \mathrm{C}$ and $7 \mathrm{MPa}$ for the catalysts prepared with different Cs or K loading amounts. As shown in Figs. S19 and S20 B, there is no detectable decline in the activity for $24 \mathrm{~h}$ as described previously.

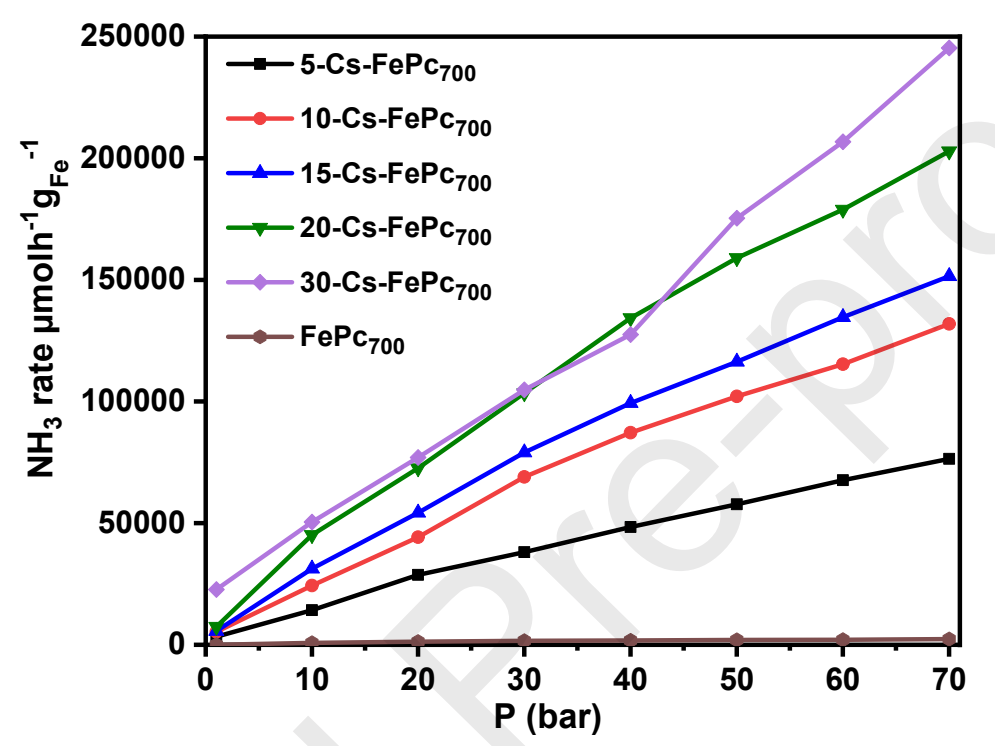

Fig. 5. Catalytic performance of the FePc derived catalysts with different Cs loading for the ammonia synthesis. $\mathrm{NH}_{3}$ synthesis rate $\mu \mathrm{mol} \mathrm{NH}_{3} \mathrm{~h}^{-1} \mathrm{~g}_{\mathrm{Fe}}{ }^{-1}$ as a function of the pressure (0.1-7 $\mathrm{MPa}$ ) at $400{ }^{\circ} \mathrm{C}$. Reaction conditions: $100 \mathrm{mg}$ of catalyst, flow rate $40 \mathrm{ml} \mathrm{min}^{-1}, \mathrm{~N}_{2}: \mathrm{H}_{2}=1: 3$, with a WHSV of $24000 \mathrm{ml} \cdot \mathrm{g}^{-1} \mathrm{~h}^{-1}$.

\subsubsection{Kinetic study}

A kinetics analysis (order with respect to $\mathrm{N}_{2}, \mathrm{H}_{2}, \mathrm{NH}_{3}$ partial pressures) was conducted for the most active catalysts (10-Cs-FePc $\mathrm{C}_{700}$ and 3-K-FePc $\mathrm{C}_{700}$ ) (Fig. 6). Apparent activation energies were measured at $6 \mathrm{MPa}$ from the Arrhenius plots (Fig. 6 A). The calculated apparent activation energy was found to be $34 \mathrm{~kJ} \mathrm{~mol}^{-1}$ and $31 \mathrm{~kJ} \mathrm{~mol}^{-1}$ for the $10-\mathrm{Cs}-\mathrm{FePC}_{700}$ and $3-\mathrm{K}_{-}-\mathrm{FePC}_{700}$ catalysts, respectively. These values can be regarded as among the lowest values reported in the literature (Table S6), whereas the apparent activation energy for the benchmark catalyst is $70 \mathrm{~kJ} \mathrm{~mol}^{-1}$ (Table 2). The activation energy strongly depends on the measurement conditions 
(pressure and activation conditions). Moreover, in the present work, we performed the activation energy for the FePc catalysts at $6 \mathrm{MPa}$, which is giving comparably lower activation energy as compared to our previous catalysts performed at $1 \mathrm{MPa}$.[30]

The Lower the value of activation energy itself suggests that there is a facile activation of $\mathrm{N}_{2}$ on the catalysts surface and preferentially hydrogenated without undergoing direct dissociation on the active site of the Fe catalyst, as demonstrated by DFT calculation. The difference in the catalytic performance between $10-\mathrm{Cs}-\mathrm{FePc}_{700}$ and $3-\mathrm{K}-\mathrm{FePC}_{700}$ catalysts (Figure $4 \mathrm{C}$ ) could be correlated with the observed apparent activation energies. [7, 28]

A

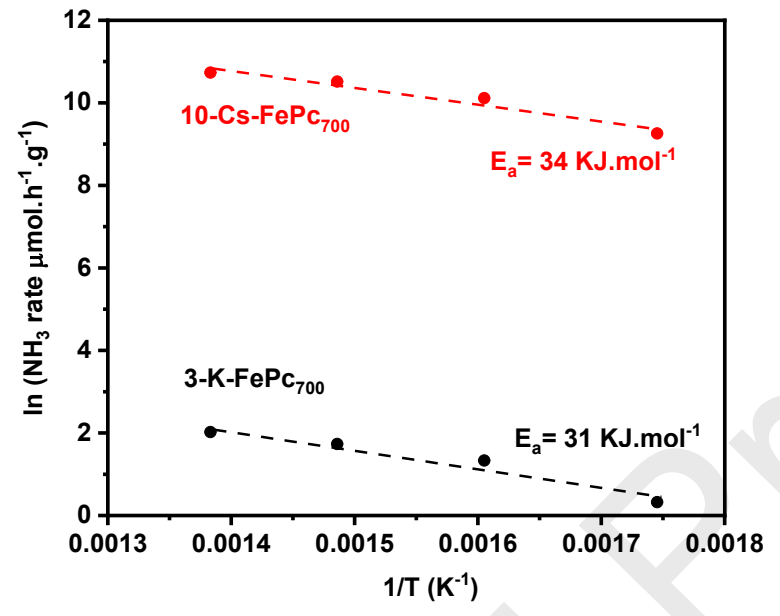

C

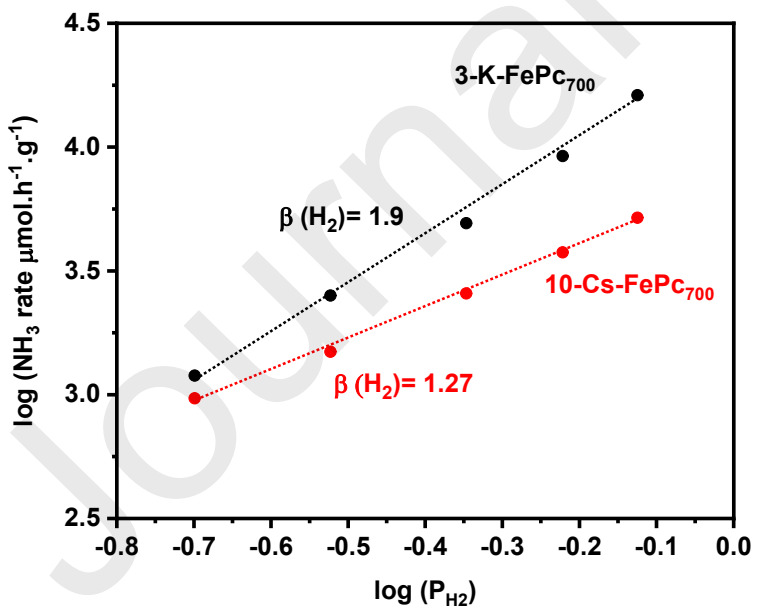

B

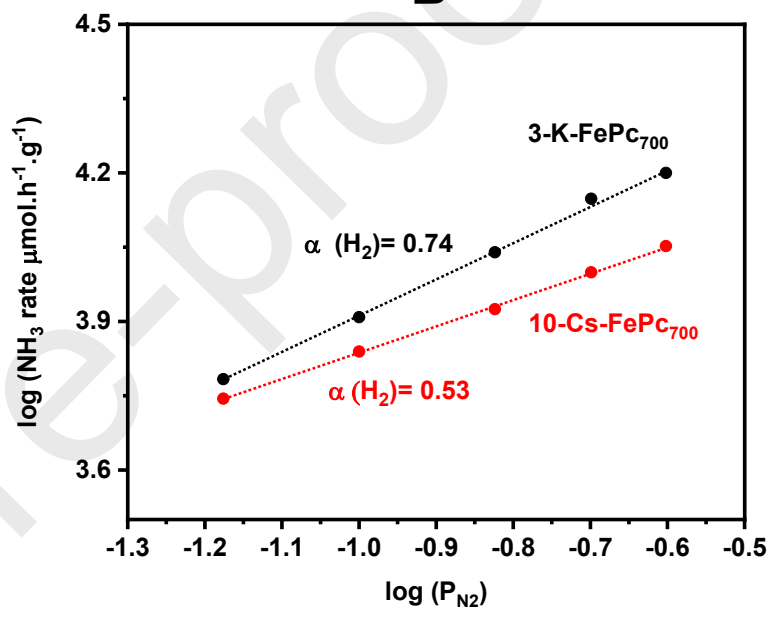

D

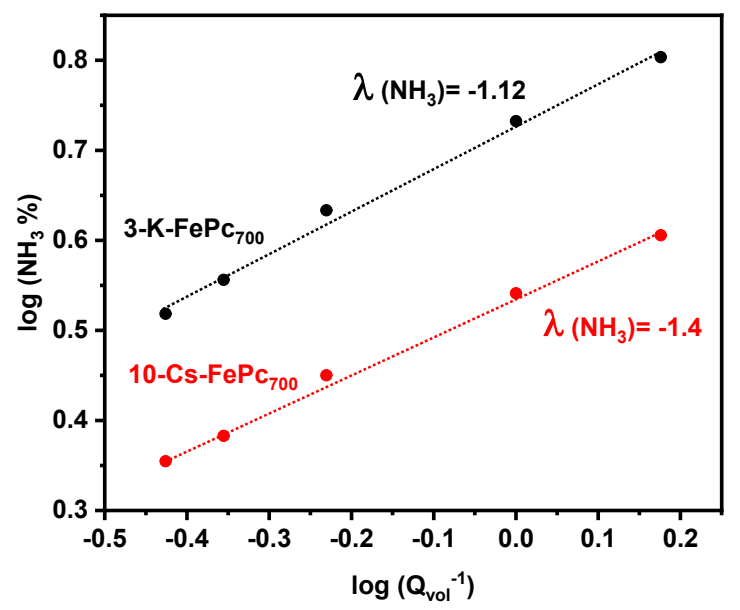

Fig. 6: Kinetic parameters of $10-\mathrm{CsFePc}_{700}$ and $3 \mathrm{~K}-\mathrm{FePC}_{700}$ catalysts for the ammonia synthesis reaction. A: Arrhenius plots at temperatures of $300-450{ }^{\circ} \mathrm{C}$ and $6 \mathrm{MPa}$. B: Dependence of the $\mathrm{NH}_{3}$-synthesis rate on the partial pressures of $\mathrm{N}_{2} \mathbf{B}, \mathrm{H}_{2} \mathbf{C}$, and $\mathrm{NH}_{3} \mathbf{D}$ at $400{ }^{\circ} \mathrm{C}$ and $1 \mathrm{MPa}$. 
Table 2: Kinetic parameters of the $10-\mathrm{CsFePC}_{700}$ and $3-\mathrm{K}-\mathrm{FePC}_{700}$ catalysts and compared to the Fe-benchmark catalyst (KM1).

\begin{tabular}{lllllc}
\hline \multicolumn{1}{c}{ Catalysts } & $E_{\mathrm{a}}\left(\mathrm{kJ} \mathrm{mol}^{-1}\right)$ & $\begin{array}{c}\mathrm{N}_{2} \text { order } \\
(\alpha)\end{array}$ & $\begin{array}{c}\mathrm{H}_{2} \text { order } \\
(\beta)\end{array}$ & $\begin{array}{c}\mathrm{NH}_{3} \text { order } \\
(\gamma)\end{array}$ & Ref. \\
\hline${ }^{[1] 10-C s F e P C_{700}}$ & 34 & 0.53 & 1.3 & -1.4 & This work \\
\hline${ }^{[1] 3-\mathrm{KFePC}_{700}}$ & 31 & 0.74 & 1.9 & -1.12 & This work \\
\hline${ }^{[2] 10 \% C s-F e P c}$ & 41.9 & 0.68 & 2.10 & -2.10 & 30 \\
\hline${ }^{[3]}$ Fe-Benchmark cat. & 70 & 0.9 & 2.2 & -1.5 & 22 \\
\hline
\end{tabular}

${ }^{[1]}$ Arrhenius plots at temperatures of $300-450{ }^{\circ} \mathrm{C}$ and $6 \mathrm{MPa} \cdot{ }^{[2]}$ and ${ }^{[3]}$ Arrhenius plots at temperatures of $300-450{ }^{\circ} \mathrm{C}$ and $1 \mathrm{MPa}$.

The reaction order with respect to $\mathrm{N}_{2}$ is varying between $0.53(\mathrm{Cs})$ and $0.74(\mathrm{~K})$ (Fig. 6 B and Table 2). The $\mathrm{N}_{2}$ reaction orders for the conventional heterogeneous catalysts are usually ranging from 0.4 to 1.0. (Table $\mathbf{S} 6$ in the SI). Further, the reaction order with respect to $\mathrm{H}_{2}$ varies between 1.3 and 1.9 (Fig. 6C and Table 2). The order observed in the literature for other conventional catalysts varies between 0.6 to 2.2. A value of 2 would correspond with the dissociation of $\mathrm{H}_{2}$ on two Fe surface atoms. A value of 2.2 is reported for the commercial benchmark iron-based catalyst.

The reaction order with respect to $\mathrm{NH}_{3}$ is -1.4 and -1.12 (Fig.6 $\mathbf{D}$ and Table 2). This observation can be interpreted in terms of the equilibrium between gaseous ammonia and adsorbed $\mathrm{NH}_{\mathrm{x}}$ species inhibiting $\mathrm{N}_{2}$ adsorption and activation.

The $\mathrm{K}$ and $\mathrm{Cs}$ promoted catalyst shows by far the best catalytic performance, and the increase in activity compared with the $\mathrm{FePc}_{700}$ without promoter catalyst is supported by the substantial increase of activity with the amount of $\mathrm{Cs}$ and $\mathrm{K}$. This improvement in activity is much more pronounced than the improvement of activity in terms of particle size. As for the objective of the present work, in order to corroborate the role of the alkali additives as structural or electronic promoters, and since it is impossible at this stage to distinguish between steric or electronic effects, a theoretical study was carried out. 
Nevertheless, these alkali metals are also linked to oxygen as " $\mathrm{K}_{2} \mathrm{O}$ " or " $\mathrm{Cs}_{2} \mathrm{O}$ ". Therefore the active form of the catalyst is a $\mathrm{Fe}^{(0)}$ particle covered by various coverage of " $\mathrm{K}_{2} \mathrm{O}$ " or " $\mathrm{Cs}_{2} \mathrm{O}$ ". The formation of these core-shell structures appears responsible for the improvement of the activity. Due to this intimate contact between " $\mathrm{K}_{2} \mathrm{O}$ " and " $\mathrm{Cs}_{2} \mathrm{O}$ " with $\mathrm{Fe}$, a strong metal-promoter interaction is likely occurring, thus giving rise to the enhanced catalytic activity of the promoted catalyst by the increasing of the number of active sites (Table 3). [70]

Table 3. Catalytic proprieties of the catalysts are prepared with various promoters.

\begin{tabular}{|c|c|c|c|c|}
\hline Catalysts & $\begin{array}{l}\text { Fe wt. } \\
(\%)\end{array}$ & $\begin{array}{l}\text { Particle size } \\
\quad(n m)^{[a]}\end{array}$ & $\begin{array}{c}\mathrm{Nb} \text {. of actives sites }(\mu \mathrm{mol} / \mathrm{g} \\
\text { of sample) }\end{array}$ & $\begin{array}{l}\mathrm{NH}_{3} \text { rate }\left(\mu \mathrm{mol} \cdot \mathrm{h}^{-1} \mathrm{~g}^{-}\right. \\
\left.{ }_{1} \text { cat }\right)^{[\mathrm{b}]}\end{array}$ \\
\hline $\mathrm{FePC}_{700}$ & 80 & 80 & 208 & 2019 \\
\hline $10-\mathrm{Cs}-\mathrm{FePC}_{700}$ & 30 & 15 & 415 & 27783 \\
\hline $3-\mathrm{K}-\mathrm{FePC}_{700}$ & 43 & 11 & 794 & 30800 \\
\hline 1.8-Na-FePc$C_{700}$ & 60 & 32 & 388 & 19760 \\
\hline $0.5-\mathrm{Li}-\mathrm{FePC}_{700}$ & 51 & 40 & 263 & 18500 \\
\hline
\end{tabular}

[a]: Average Fe particle size, and number of active site were determine by TEM. ${ }^{[b]}: \mathrm{NH}_{3}$ rate $\left(\mu \mathrm{molh}^{-1} . \mathrm{g}_{\text {cat. }}{ }^{-}\right.$ 1), conditions: $\mathrm{P}=7 \mathrm{MPa}$, and $\mathrm{T}=400^{\circ} \mathrm{C}$.

\subsection{Theoretical study}

\subsubsection{DFT structural information}

DFT calculations on the two Cs- and K-containing Fe catalysts were analyzed in order to understand the origin (geometric or electronic effect) behind the difference in their catalytic performance observed experimentally. Fig. 7 displays the most stable structures of $\mathrm{Fe}(110)$ $\left(\mathrm{Cs}_{2} \mathrm{O}\right)_{\mathrm{n}}$ and $\mathrm{Fe}(110)-\left(\mathrm{K}_{2} \mathrm{O}\right)_{\mathrm{n}}$ catalysts (with $\mathrm{n}=2,3$, and 4). Some of the metastable configurations, particularly for $n=4$ are given in the SI (Figs. S21-S22). As reported in the literature, $\mathrm{Fe}(110)$ has been known as an active surface for ammonia synthesis but shows lower activity as compared to $\mathrm{Fe}(111)$ and Fe(211) surfaces. The choice of Fe(110) plane in DFT calculation is based on the XRD pattern obtained for $10-\mathrm{Cs}_{-}-\mathrm{FePC}_{600}$ and $10-\mathrm{Cs}-\mathrm{FePc}_{700}$ catalysts, which show a very sharp and intense peak at the $45^{\circ}(2 \theta)$, corresponds to Fe(110) (Fig. S7), which 
is the most abundant and stable surface. Therefore, we chose Fe(110) plane to perform the DFT calculations, which might help to inspire the real catalyst structure.

In both cases, the structures were highly unstable when all the $O$ species are located above the alkali species without the formation of any $\mathrm{Fe}-\mathrm{O}$ bond. However, their stability was getting systematically enhanced when more and more $\mathrm{O}$ species are intercalated in between alkali layers and Fe surface (Figs. S21-S22).

The structures were finally strongly stabilized when all the $O$ species are intercalated in between the alkali layers and Fe surface with the maximal number of Fe-O bonds (Figs. S21-S22). In the lowest-energy structures, the $\mathrm{Cs}, \mathrm{K}$, and $\mathrm{O}$ species are homogeneously distributed over the $\mathrm{Fe}(110)$ surface and preferentially adopt a double-layer structure where the first sublayer on top of the iron surface is made by $\mathrm{O}$ species and the second layer above the first one is made by $\mathrm{Cs}$ or $\mathrm{K}$ species, as shown in Fig. 7.

The most stable structures reveal well-oriented and dispersed " $\mathrm{Cs}_{2} \mathrm{O}$ " and " $\mathrm{K}_{2} \mathrm{O}$ " species, in which each $\mathrm{O}$ species is sitting on a triangle of $\mathrm{Fe}$ with $\mathrm{O}-\mathrm{Fe}$ bond length of $1.9 \AA$ and the two neighboring alkali elements are sitting on squares of Fe with $\mathrm{Cs}$-Fe non-bonding distances ranging from 3.3 to $3.8 \AA$, Cs-O bond length of $2.9 \AA$, K-Fe non-bonding distances ranging from 3.1 to $3.4 \AA$, and $\mathrm{K}-\mathrm{O}$ bond length of $2.8 \AA$. The " $\mathrm{Cs}_{2} \mathrm{O}$ " species are separated between each other by nearest $\mathrm{Cs}$ Cs distances ranging from 4.7 to $7.9 \AA$ with decreasing Cs loading from $n=4$ to $n=2$. The " $\mathrm{K}_{2} \mathrm{O}$ " species are separated between each other by larger nearest $\mathrm{K}-\mathrm{K}$ distances ranging from 4.6 to $7.9 \AA$ with decreasing $\mathrm{K}$ loading from $\mathrm{n}=4$ to $\mathrm{n}=2$. These results lead to almost complete coverage of Fe surface, in good agreement with the obtained HAADF-STEM images of 10-CsFePc and 3-K-FePc catalysts (Fig. 2).

Our predicted structures are in pretty good agreement with the previous work published by Arabczyk and co-workers. [61] Interestingly, as Cs size is much larger than $\mathrm{K}$, almost all of Cs species are deposited on squares of $\mathrm{Fe}$ while some of $\mathrm{K}$ species are displaced from Fe squares towards other neighbor $\mathrm{K}$ species in order to bind strongly with $\mathrm{O}$ and maintain the same $\mathrm{K}-\mathrm{O}$ bond length of $2.7 \AA$.

This leads to a more significant number of exposed $\mathrm{Fe}$ atoms in the case of $\mathrm{K}$ than $\mathrm{Cs}$, as highlighted in Fig. 7. As a consequence, the number of active sites is expected to be larger in the case of $\mathrm{K}$ than $\mathrm{Cs}$, and therefore, this geometrical discrepancy is expected to leave an impact on the catalytic performance results, as observed in Fig. 4, described before. 
The thermodynamic stability was also studied by DFT calculations to evaluate the possible formation of $\mathrm{Fe}(110)-\mathrm{Cs}_{2 \mathrm{n}}$ and $\mathrm{Fe}(110)-\mathrm{K}_{2 \mathrm{n}}$ catalysts by treating $\mathrm{Fe}(110)-\left(\mathrm{Cs}_{2} \mathrm{O}\right) \mathrm{n}$ and $\mathrm{Fe}(110)-$ $\left(\mathrm{K}_{2} \mathrm{O}\right)_{\mathrm{n}}$ catalysts under hydrogen following the experimental conditions and the possible release of water from the reaction. The thermodynamic diagram is shown in Fig. 8. As can be clearly seen, $\mathrm{Fe}(110)-\left(\mathrm{Cs}_{2} \mathrm{O}\right)_{\mathrm{n}}$ and $\mathrm{Fe}(110)-\left(\mathrm{K}_{2} \mathrm{O}\right)_{\mathrm{n}}$ catalysts are thermodynamically much more stable than $\mathrm{Fe}(110)-\mathrm{Cs}_{2 n}$ and $\mathrm{Fe}(110)-\mathrm{K}_{2 n}$ catalysts throughout this hydrogen chemical potential.

This result confirms the necessary presence of $O$ species in line with the experimental observations. In order to get relevant information about any possible direct electron transfer between $\mathrm{Cs}$ or $\mathrm{K}$ and $\mathrm{Fe}$ support, the analysis was performed on the most stable structures of $\mathrm{Fe}(110)-\left(\mathrm{Cs}_{2} \mathrm{O}\right)_{\mathrm{n}}$ and $\mathrm{Fe}(110)-\left(\mathrm{K}_{2} \mathrm{O}\right)_{\mathrm{n}}$ catalysts. In both cases, Bader charge analysis revealed slightly positive charges of $\mathrm{Fe}$ linked to $\mathrm{O}$ (with a loss of 0.2 fractions of the electron; $\mathrm{Fe}^{(+0.2)}$ ). While those directly coordinated with $\mathrm{Cs}$ and $\mathrm{K}$, or even the exposed surface Fe revealed slightly negative charges (with a gain of 0.1 to 0.16 fraction of electron; $\mathrm{Fe}^{(-0.13)}$ ).

By comparing the DFT-based predicted atomic and electronic structures of $\mathrm{Fe}(110)-\left(\mathrm{Cs}_{2} \mathrm{O}\right)_{\mathrm{n}}$ and $\mathrm{Fe}(110)-\left(\mathrm{K}_{2} \mathrm{O}\right)_{\mathrm{n}}$ catalysts, we could see a similarity in the charge distribution of surface Fe species, while the main discrepancy was related to the geometrical repartition of alkali species. This fundamental aspect might explain the difference in the catalytic results. This corroborates that geometrical effect becomes more important than the electronic impact in the role of alkali metal additives. 

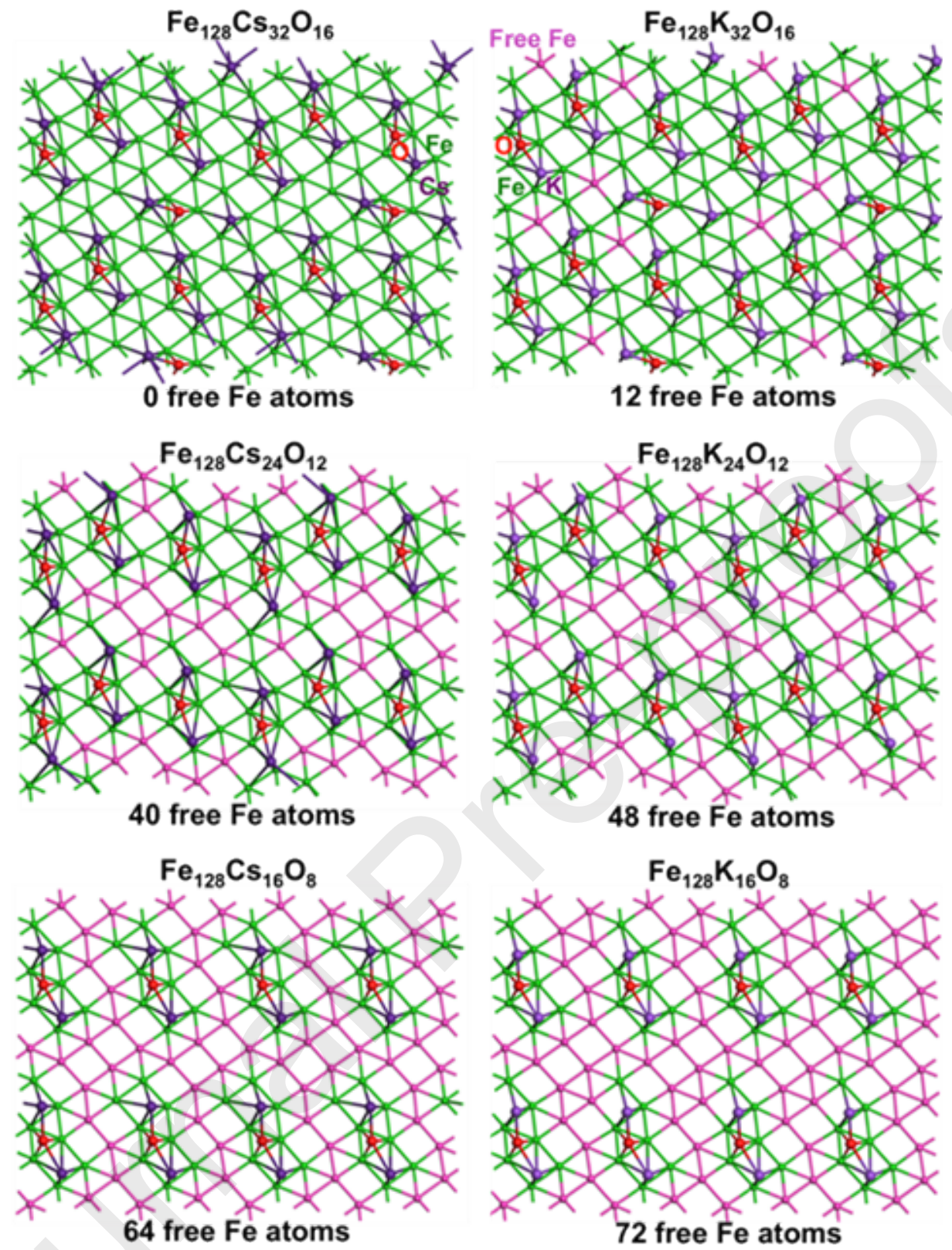

Fig. 7. Top view depictions $(8 \times 8)$ of the DFT-based most stable structures of $\left.\mathrm{Fe}(110)-\mathrm{Cs}_{2} \mathrm{O}\right)_{n}$ (on the left) and $\mathrm{Fe}(110)-\left(\mathrm{K}_{2} \mathrm{O}\right)_{n}$ (on the right) catalysts with $\mathrm{n}=2,3$, and 4. Color legend: $\mathrm{Fe}$ in green, $\mathrm{Cs}$ in dark purple, $\mathrm{K}$ in light purple, $\mathrm{O}$ in red, and exposed $\mathrm{Fe}$ in pink. The number of surface atoms is given above each structure. The number of exposed Fe atoms is given below each structure.

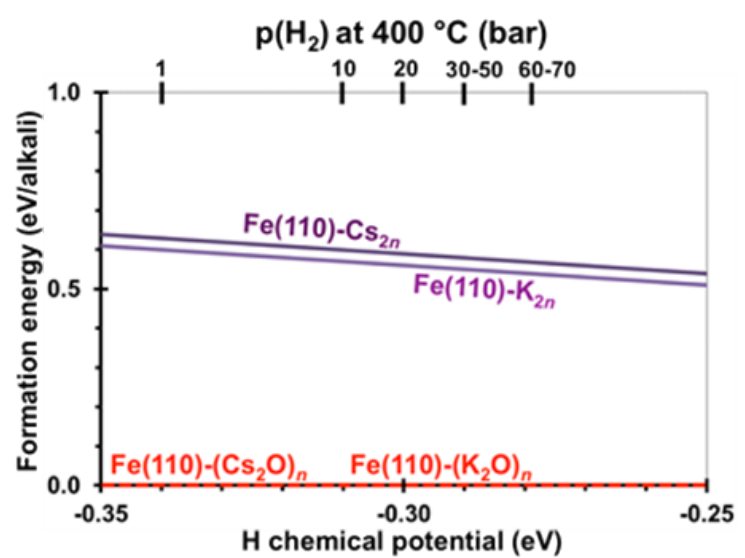


Fig. 8. DFT-based computed formation energy of $\mathrm{Fe}(110)-\left(\mathrm{Cs}_{2} \mathrm{O}\right)_{n}$ and $\mathrm{Fe}(110)-\left(\mathrm{K}_{2} \mathrm{O}\right)_{n}$ catalysts as a function of hydrogen chemical potential at $400{ }^{\circ} \mathrm{C}$ with released water at atmospheric pressure. The dashed red line with zero formation energy represents $\mathrm{Fe}(110)-\left(\mathrm{Cs}_{2} \mathrm{O}\right)_{n}$ and $\mathrm{Fe}(110)-\left(\mathrm{K}_{2} \mathrm{O}\right)_{n}$ catalysts.

\subsubsection{DFT mechanistic information}

Finally, DFT calculations were also carried out to illustrate the mechanism of $\mathrm{N}_{2}$ activation and reduction to ammonia. The modeling of the reaction pathway was conducted, especially on a medium loading of $\mathrm{K}$ as a typical example. Fig. 9 illustrates the change in the free energy profile with pressure, at a temperature of $400{ }^{\circ} \mathrm{C}$. Since the experiments were performed in excess of $\mathrm{H}_{2}$ and high pressure of $7 \mathrm{MPa}$, we first adsorbed three dihydrogen on $\mathrm{K}_{2} \mathrm{O} / \mathrm{Fe}(110)$ consecutively. The three $\mathrm{H}_{2}$ are adsorbed dissociatively (binding energy ranging approximately between -20 to $-30 \mathrm{kcal}^{\mathrm{mol}}{ }^{-1}$ ) on the $\mathrm{Fe}$ surface near the $\mathrm{K}_{2} \mathrm{O}$ clusters. Dinitrogen is adsorbed near this dissociated $\mathrm{H}_{2}$ with a binding energy of $\sim-15 \mathrm{kcal}^{\text {mol-1 }}{ }^{-1}$ by an end-on-mode (non-dissociative) (Fig. 9). The triple $\mathrm{N} \equiv \mathrm{N}$ bond is subsequently cleaved with gradual hydrogenation of the specific $\mathrm{N}$ atom not bound to $\mathrm{Fe}$, leading stepwise to the release of the first $\mathrm{NH}_{3}$ molecule. This type of NRR (nitrogen reduction reaction) is classified by previous studies as a distal associative pathway. $[72,73]$ The second $\mathrm{NH}_{3}$ is also thermodynamically favorable as the first $\mathrm{NH}_{3}$ is released from the surface. As seen in the free energy profile of Fig. 9, the intermediates become thermodynamically more feasible with increasing pressure. At atmospheric pressure and $400{ }^{\circ} \mathrm{C}$, $\mathrm{N}_{2}$ adsorption is thermodynamically unfavorable (by $\sim 10 \mathrm{kcal}^{\mathrm{mol}}{ }^{-1}$ ) in the presence of excess $\mathrm{H}$ atoms on the Fe surface. As the pressure increases to $1 \mathrm{MPa}$, the reaction profile becomes downhill, and the $\mathrm{N}_{2}$ is adsorbed at $\sim 7 \mathrm{kcal}^{\mathrm{mol}}{ }^{-1}$, the binding energy gradually increases with increasing pressure. Therefore, the thermodynamic stability of the reaction intermediates for NRR increases with increasing pressure. This indicates better feasibility of the ammonia production at higher pressures, which is in good agreement with the experimental data described previously (Fig. 4).

As a conclusion of the DFT studies on the localization of promoters and the resulting mechanism, we can say that, in agreement with experiment results, the promoters are localized on the $\mathrm{Fe}^{(0)}$ 
as " $\mathrm{K}_{2} \mathrm{O}$ " or " $\mathrm{Cs}_{2} \mathrm{O}$ ". This coordination leaves some free space for $\mathrm{Fe}^{(0)}$ and molecular $\mathrm{N}_{2}$ coordination. This coordination is "end on" on a unique Fe atom. Then, there is a progressive stepwise addition of hydrogen on the distal $\mathrm{N}$ and the closer $\mathrm{N}$ leading to ammonia.
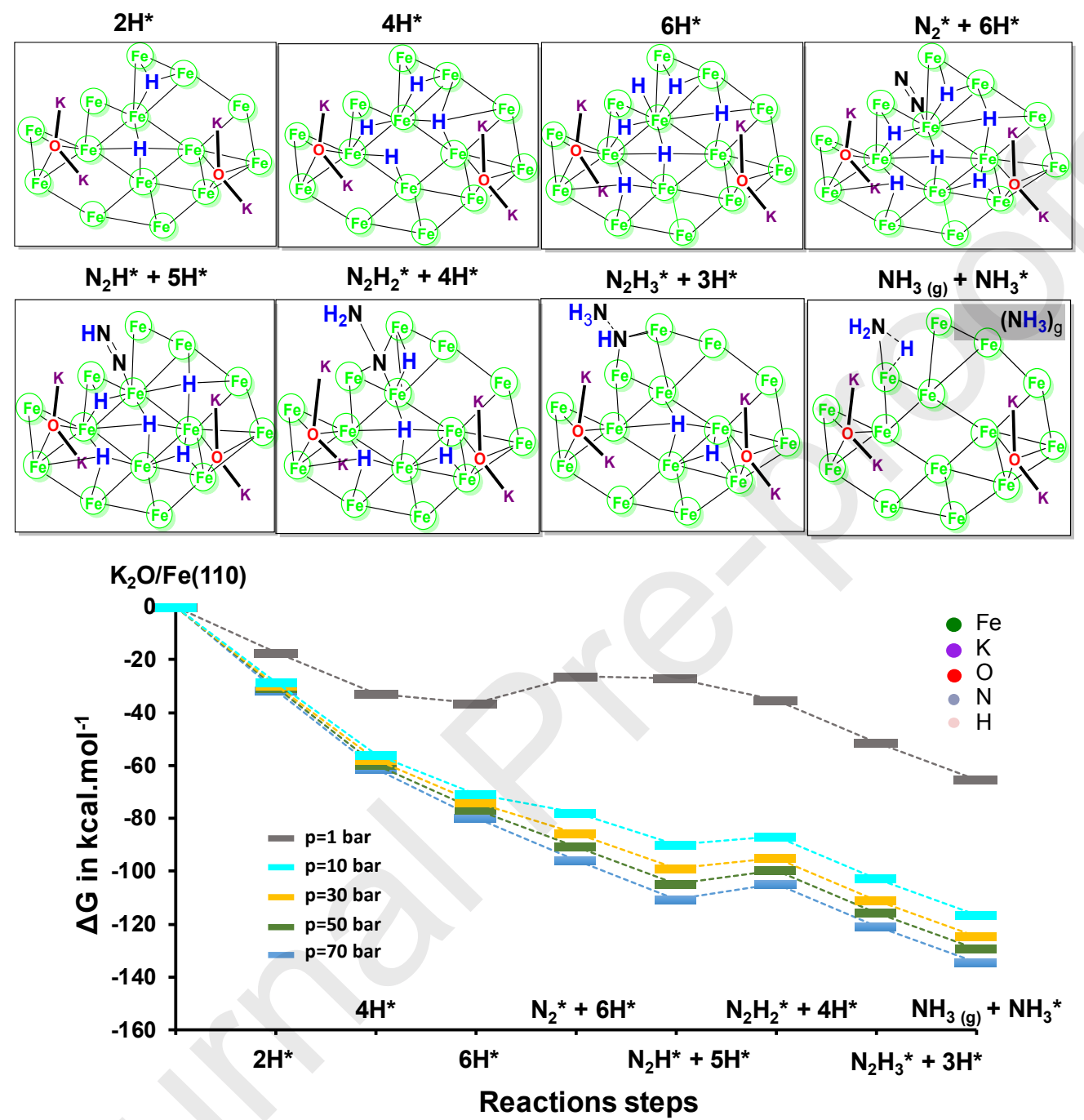

Fig. 9. Gibbs free energy $(\Delta \mathrm{G})$ profile close to the experimental reaction temperature of $400{ }^{\circ} \mathrm{C}$ of $\mathrm{N}_{2}$ hydrogenation to $\mathrm{NH}_{3}$ on $\mathrm{K}_{2} \mathrm{O} / \mathrm{Fe}$ (110). The insets are zoomed c-view of the surface where the hydrogen attack the $\mathrm{N}_{2}$ to show the geometries of the reaction intermediates. The corresponding DFT-based geometries of the intermediate structures of NRR to the ChemDraw drawings are given in the SI (Fig. S23).

\section{Conclusion}

In summary, we have successfully prepared Fe NPs supported on carbon by pyrolysis of FePc under $\mathrm{N}_{2}$ followed by treatment under $\mathrm{H}_{2}$. These NPs were found to be very active and stable 
catalysts for ammonia synthesis, as compared to the commercial iron-based catalyst from HaldorTopsoe, widely used for the ammonia synthesis process.

Extensive characterization was applied at various stages of the preparation. Nano-sized coreshell structures were formed during $\mathrm{H}_{2}$ pretreatment, with Fe NPs located in the core and oxygenalkali metals located on the shell. The alkali metals and their loading played critical roles in the particle size distribution. They also partially inhibited the methanation process of carbon, which occurs during the $\mathrm{H}_{2}$ pretreatment. Increasing the pyrolysis temperature increased the iron particle size and encapsulation of iron into the carbon support was observed at ca. $800{ }^{\circ} \mathrm{C}$.

The activities for FePc catalysts promoted with various promoters followed the order: $\mathrm{K}>\mathrm{Cs}>\mathrm{Na} \sim \mathrm{Li}$. The optimal catalytic performance was obtained with a catalyst prepared by pyrolysis at $600{ }^{\circ} \mathrm{C}$ promoted with $10 \%$ wt. Cs or at $700{ }^{\circ} \mathrm{C}$ promoted by $3 \%$ wt. of $\mathrm{K}$, reaching more than $6 \%$ of $\mathrm{NH}_{3}$ at $400{ }^{\circ} \mathrm{C}$ and $7 \mathrm{MPa}$ at a WHSV of $12000 \mathrm{ml} \cdot \mathrm{g}^{-1} \cdot \mathrm{h}^{-1}$, with no observable deactivation over $72 \mathrm{~h}$.

The apparent activation energy for ammonia synthesis was found to be $31 \mathrm{~kJ}^{\mathrm{mol}}{ }^{-1}$ and $34 \mathrm{~kJ}^{\mathrm{mol}}{ }^{-}$ 1 for $3-\mathrm{K}-\mathrm{FePc}_{700}$ and $10-\mathrm{Cs}-\mathrm{FePc}_{700}$ catalysts, respectively, suggesting the facile activation of $\mathrm{N}_{2}$ on the catalysts surface. Further, kinetic studies reveal the reaction order with respect to $\mathrm{N}_{2}$ is close to unity (0.7). The reaction order with respect to $\mathrm{H}_{2}$ is close to 1.5 , suggesting the dissociation of $\mathrm{H}_{2}$ on two $\mathrm{Fe}$ surface atoms. The negative order (-1.3) with respect to $\mathrm{NH}_{3}$ suggesting that ammonia is equilibrium with the $\mathrm{NH}_{\mathrm{x}}$ species on the catalysis surface. The main discrepancy was related to the geometrical repartition of alkali species, leading to a larger number of exposed iron, active sites, in the case of $\mathrm{K}$ than $\mathrm{Cs}$.

The predicted thermodynamic results showed that the alkali present under the form of " $\mathrm{M}_{2} \mathrm{O}$ " $(\mathrm{M}=$ Cs and K) cannot be reduced even at high temperature and hydrogen pressure, confirming the necessary presence of $O$ species in line with the experimental observations. The metal oxide leaves at medium coverage of the surface some exposed iron for $\mathrm{N}_{2}$ non-dissociative chemisorption (end-on type).

Regarding the mechanism of ammonia synthesis at a molecular level, a DFT-based mechanistic study for $\mathrm{N}_{2}$ activation and reduction was conducted mainly for $\mathrm{Fe}(110)-\mathrm{K}_{2} \mathrm{O}$ catalyst. The free energy profile demonstrated that the thermodynamic stability of the reaction intermediates for Nitrogen Reduction Reaction (NRR) increased with increasing pressure, indicating better feasibility of the reaction at higher pressures, which is in good agreement with the experiment data. 
This study, based on an in-depth analysis of the structure-activity relationship, allowed us to bring a precise picture of the role of the alkali metals in the ammonia synthesis process. Furthermore, DFT calculations were also applied to probe the feasibility of associative mechanism with the stepwise addition of hydrogen, as we have previously demonstrated on a single $\mathrm{Ta}$ atom on silica.[18] This observation still opens the question of the role of dissociated forms of nitrogen $\left(\mathrm{NH}_{\mathrm{x}}\right)$, which are certainly observed under certain conditions. They have been claimed as intermediates in the mechanism of ammonia synthesis, but the main conclusion of this DFT mechanistic approach seems to indicate that they are not involved in the mechanism of ammonia synthesis.

\section{Acknowledgments}

This research was supported by SABIC Company. The authors acknowledge the resources and facilities provided by the King Abdullah University of Science and Technology. The authors acknowledge as well the KAUST Analytical Core Lab (ACL), particularly the scientists Mohammed Khalid and Dr. Omar EI Tall. The authors acknowledge as well the KAUST Imaging Core Lab, particularly Dr. Alessandro Genovese. M.H., R.A., and L.C. acknowledge the KAUST Supercomputing Laboratory for providing computational resources using the supercomputer Shaheen II.

\section{Reference}

[1] A. Klerke, C.H. Christensen, J.K. Nørskov, T. Vegge, Ammonia for hydrogen storage: challenges and opportunities, J. Mater. Chem., 18 (2008) 2304-2310.

[2] J. Kammert, J. Moon, Y. Cheng, L. Daemen, S. Irle, V. Fung, J. Liu, K. Page, X. Ma, V. Phaneuf, J. Tong, A.J. Ramirez-Cuesta, Z. Wu, Nature of Reactive Hydrogen for Ammonia Synthesis over a Ru/C12A7 Electride Catalyst, J. Am. Chem. Soc., 142 (2020) 7655-7667.

[3] L. Wang, M. Xia, H. Wang, K. Huang, C. Qian, C.T. Maravelias, G.A. Ozin, Greening Ammonia toward the Solar Ammonia Refinery, Joule, 2 (2018) 1055-1074.

[4] Y. Tang, Y. Kobayashi, N. Masuda, Y. Uchida, H. Okamoto, T. Kageyama, S. Hosokawa, F. Loyer, K. Mitsuhara, K. Yamanaka, Y. Tamenori, C. Tassel, T. Yamamoto, T. Tanaka, H. Kageyama, Metal-Dependent Support Effects of Oxyhydride-Supported Ru, Fe, Co Catalysts for Ammonia Synthesis, Adv. Energy Mater., 8 (2018) n/a.

[5] J. Humphreys, R. Lan, S. Chen, S. Tao, Improved stability and activity of Fe-based catalysts through strong metal support interactions due to extrinsic oxygen vacancies in Ce0.8Sm0.2O2- $\delta$ for the efficient synthesis of ammonia, J. Mater. Chem. A, 8 (2020) 16676-16689. 
[6] T.H. Rod, A. Logadottir, J.K. Nørskov, Ammonia synthesis at low temperatures, J. Chem. Phys., 112 (2000) 5343-5347.

[7] C.J.H. Jacobsen, S. Dahl, B.S. Clausen, S. Bahn, A. Logadottir, J.K. Nørskov, Catalyst Design by Interpolation in the Periodic Table: Bimetallic Ammonia Synthesis Catalysts, J. Am. Chem. Soc., 123 (2001) 8404-8405.

[8] V.B. Shur, S.M. Yunusov, On the path to catalysts for the low-temperature ammonia synthesis, Russ. Chem. Bull., 47 (1998) 765-776.

[9] H. Liu, Ammonia Synthesis Catalysts Innovation and Practice, Ammonia Synthesis Catalysts Innovation and Practice, (2013).

[10] G. Ertl, S.B. Lee, M. Weiss, Adsorption of nitrogen on potassium promoted Fe(111) and (100) surfaces, Surf. Sci., 114 (1982) 527-545.

[11] D.C. Silverman, M. Boudart, Surface composition of promoted iron catalysts, J. Catal., 77 (1982) 208-220.

[12] M. Bowker, Chapter 7 - Promotion in Ammonia Synthesis, in: D.A. King, D.P. Woodruff (Eds.) The Chemical Physics of Solid Surfaces, Elsevier, 1993, pp. 225-268.

[13] J. Li, X. Cheng, C. Zhang, J. Wang, W. Dong, Y. Yang, Y. Li, Alkalis in iron-based FischerTropsch synthesis catalysts: distribution, migration and promotion, J. Chem. Tech. Biotech., 92 (2017) 1472-1480.

[14] H.D. Vandervell, K.C. Waugh, On the role of promoters in promoted iron catalysts used in the industrial synthesis of ammonia, Chem. Phys. Lett., 171 (1990) 462-468.

[15] J.G. van Ommen, W.J. Bolink, J. Prasad, P. Mars, The nature of the potassium compound acting as a promoter in iron-alumina catalysts for ammonia synthesis, J. Catal., 38 (1975) 120127.

[16] D.R. Strongin, G.A. Somorjai, The effects of potassium on ammonia synthesis over iron single-crystal surfaces, J. Catal., 109 (1988) 51-60.

[17] R. Egeberg, S. Dahl, A. Logadottir, J.H. Larsen, J.K. Nørskov, I. Chorkendorff, $\mathrm{N}_{2}$ dissociation on $\mathrm{Fe}(110)$ and Fe/Ru(0001): What is the role of steps?, Surf. Sci., 491 (2001) 183-194.

[18] P. Avenier, M. Taoufik, A. Lesage, X. Solans-Monfort, A. Baudouin, A. de Mallmann, L. Veyre, J.-M. Basset, O. Eisenstein, L. Emsley, E.A. Quadrelli, Dinitrogen Dissociation on an Isolated Surface Tantalum Atom, Science, 317 (2007) 1056-1060.

[19] Y. Gong, J. Wu, M. Kitano, J. Wang, T.-N. Ye, J. Li, Y. Kobayashi, K. Kishida, H. Abe, Y. Niwa, H. Yang, T. Tada, H. Hosono, Ternary intermetallic LaCoSi as a catalyst for $\mathrm{N}_{2}$ activation, Nat. Catal., 1 (2018) 178-185.

[20] S. Wang, F. Ichihara, H. Pang, H. Chen, J. Ye, Nitrogen Fixation Reaction Derived from Nanostructured Catalytic Materials, Adv. Funct. Mater., 28 (2018) 1803309. 
[21] D. R. Strongin, G.A. Somorjai;, Catalytic Ammonia Synthesis Fundamentals and Practice, Edited by J .R. Jennings Plenum Press, New York, (1991).

[22] S. Hagen, R. Barfod, R. Fehrmann, C.J.H. Jacobsen, H.T. Teunissen, K. Ståhl, I. Chorkendorff, New efficient catalyst for ammonia synthesis: barium-promoted cobalt on carbon, Chem. Commun., (2002) 1206-1207.

[23] S.R. Bare, D.R. Strongin, G.A. Somorjai, Ammonia synthesis over iron single-crystal catalysts: the effects of alumina and potassium, J. Phys. Chem., 90 (1986) 4726-4729.

[24] R. Schlögl, Ammonia Synthesis. In Handbook of Heterogeneous Catalysis;, Wiley-VCH Verlag $\mathrm{GmbH} \&$ Co. KGaA, (2008).

[25] R. Kojima, K.-i. Aika, Cobalt molybdenum bimetallic nitride catalysts for ammonia synthesis: Part 2. Kinetic study, Appl. Catal. A, 218 (2001) 121-128.

[26] X. Solans-Monfort, C. Chow, E. Goure, Y. Kaya, J.-M. Basset, M. Taoufik, E.A. Quadrelli, O. Eisenstein, Successive Heterolytic Cleavages of $\mathrm{H}_{2}$ Achieve $\mathrm{N}_{2}$ Splitting on Silica-Supported Tantalum Hydrides: A DFT Proposed Mechanism, Inorg. Chem., 51 (2012) 7237-7249.

[27] H.-P. Jia, E.A. Quadrelli, Mechanistic aspects of dinitrogen cleavage and hydrogenation to produce ammonia in catalysis and organometallic chemistry: relevance of metal hydride bonds and dihydrogen, Chem. Soc. Rev., 43 (2014) 547-564.

[28] J.-C. Liu, X.-L. Ma, Y. Li, Y.-G. Wang, H. Xiao, J. Li, Heterogeneous Fe3 single-cluster catalyst for ammonia synthesis via an associative mechanism, Nat. Commun., 9 (2018) 1610.

[29] X. Wang, X. Peng, W. Chen, G. Liu, A. Zheng, L. Zheng, J. Ni, C.-t. Au, L. Jiang, Insight into dynamic and steady-state active sites for nitrogen activation to ammonia by cobalt-based catalyst, Nat. Commun., 11 (2020) 653.

[30] N. Morlanes, W. Almaksoud, R.K. Rai, S. Ould-Chikh, M.M. Ali, B.E. Al-Sabban, B. Vidjayacoumar, K. Al-Bahily, J.-M. Basset, Development of catalysts for ammonia synthesis based on metal phthalocyanine materials, Catal. Sci. Technol., (2020) 10, 844-852.

[31] H. Tüysüz, F. Schüth, L. Zhi, K. Müllen, M. Comotti, Ammonia Decomposition over Iron Phthalocyanine-Based Materials, ChemCatChem, 7 (2015) 1453-1459.

[32] L. Zhi, T. Gorelik, R. Friedlein, J. Wu, U. Kolb, W.R. Salaneck, K. Müllen, Solid-State Pyrolyses of Metal Phthalocyanines: A Simple Approach towards Nitrogen-Doped CNTs and Metal/Carbon Nanocables, Small, 1 (2005) 798-801.

[33] A. Aijaz, N. Fujiwara, Q. Xu, From Metal-Organic Framework to Nitrogen-Decorated Nanoporous Carbons: High $\mathrm{CO}_{2}$ Uptake and Efficient Catalytic Oxygen Reduction, J. Am. Chem. Soc., 136 (2014) 6790-6793.

[34] Z. Xiang, D. Cao, L. Huang, J. Shui, M. Wang, L. Dai, Nitrogen-Doped Holey Graphitic Carbon from 2D Covalent Organic Polymers for Oxygen Reduction, Adv. Mater., 26 (2014) 3315-3320. 
[35] J. Sehested, C.J.H. Jacobsen, E. Törnqvist, S. Rokni, P. Stoltze, Ammonia Synthesis over a Multipromoted Iron Catalyst: Extended Set of Activity Measurements, Microkinetic Model, and Hydrogen Inhibition, J. Catal., 188 (1999) 83-89.

[36] S. Cimino, F. Boccia, L. Lisi, Effect of alkali promoters ( $\mathrm{Li}, \mathrm{Na}, \mathrm{K})$ on the performance of $\mathrm{Ru} / \mathrm{Al}_{2} \mathrm{O}_{3}$ catalysts for $\mathrm{CO}_{2}$ capture and hydrogenation to methane, J. $\mathrm{CO}_{2}$ Util., 37 (2020) 195203.

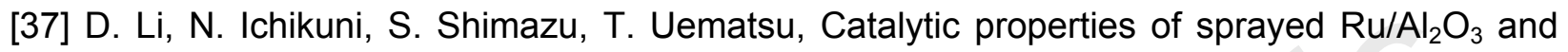
promoter effects of alkali metals in $\mathrm{CO}_{2}$ hydrogenation, Appl. Catal. A, 172 (1998) 351-358.

[38] K.-i. Aika, Role of alkali promoter in ammonia synthesis over ruthenium catalysts-Effect on reaction mechanism, Catal. Today, 286 (2017) 14-20.

[39] P.E. Blöchl, Projector augmented-wave method, Phys. Rev. B, 50 (1994) 17953-17979.

[40] G. Kresse, J. Hafner, Ab initio molecular-dynamics simulation of the liquid-metal-amorphoussemiconductor transition in germanium, Phys. Rev. B Condens. Matter., 49 (1994) 14251-14269.

[41] G. Kresse, J. Furthmüller, Efficient iterative schemes for ab initio total-energy calculations using a plane-wave basis set, Phys. Rev. B, 54 (1996) 11169-11186.

[42] G. Kresse, J. Furthmüller, Efficiency of ab-initio total energy calculations for metals and semiconductors using a plane-wave basis set, Comput. Mater. Sci., 6 (1996) 15-50.

[43] G. Kresse, D. Joubert, From ultrasoft pseudopotentials to the projector augmented-wave method, Phys. Rev. B, 59 (1999) 1758-1775.

[44] J.P. Perdew, K. Burke, M. Ernzerhof, Generalized Gradient Approximation Made Simple, Phys. Rev. Lett., 77 (1996) 3865-3868.

[45] H.J. Monkhorst, J.D. Pack, Special points for Brillouin-zone integrations, Phys. Rev. B, 13 (1976) 5188-5192.

[46] B. Delley, From molecules to solids with the DMol(3) approach, J. Chem. Phys., 113 (2000) 7756-7764.

[47] B. Delley, An All-Electron Numerical-Method for Solving the Local Density Functional for Polyatomic-Molecules, J. Chem. Phys., 92 (1990) 508-517.

[48] H. Zhu, D.C. Rosenfeld, M. Harb, D.H. Anjum, M.N. Hedhili, S. Ould-Chikh, J.-M. Basset, Ni$\mathrm{M}-\mathrm{O}(\mathrm{M}=\mathrm{Sn}, \mathrm{Ti}, \mathrm{W})$ Catalysts Prepared by a Dry Mixing Method for Oxidative Dehydrogenation of Ethane, ACS Catal., 6 (2016) 2852-2866.

[49] J.-W. Jang, D. Friedrich, S. Müller, M. Lamers, H. Hempel, S. Lardhi, Z. Cao, M. Harb, L. Cavallo, R. Heller, R. Eichberger, R. van de Krol, F.F. Abdi, Enhancing Charge Carrier Lifetime in Metal Oxide Photoelectrodes through Mild Hydrogen Treatment, Adv. Energy Mater., 7 (2017) 1701536. 
[50] M. Lamers, W. Li, M. Favaro, D.E. Starr, D. Friedrich, S. Lardhi, L. Cavallo, M. Harb, R. van de Krol, L.H. Wong, F.F. Abdi, Enhanced Carrier Transport and Bandgap Reduction in SulfurModified $\mathrm{BiVO}_{4}$ Photoanodes, Chem. Mater., 30 (2018) 8630-8638.

[51] J.-i. Ozaki, K. Nozawa, K. Yamada, Y. Uchiyama, Y. Yoshimoto, A. Furuichi, T. Yokoyama, A. Oya, L.J. Brown, J.D. Cashion, Structures, physicochemical properties and oxygen reduction activities of carbons derived from ferrocene-poly(furfuryl alcohol) mixtures, J. Appl. Electrochem., 36 (2006) 239-247.

[52] P. Yan, W. Guo, Z. Liang, W. Meng, Z. Yin, S. Li, M. Li, M. Zhang, J. Yan, D. Xiao, R. Zou, D. Ma, Highly efficient K-Fe/C catalysts derived from metal-organic frameworks towards ammonia synthesis, Nano Res., 12 (2019) 2341-2347.

[53] W. Raróg-Pilecka, A. Jedynak-Koczuk, J. Petryk, E. Miśkiewicz, S. Jodzis, Z. Kaszkur, Z. Kowalczyk, Carbon-supported cobalt-iron catalysts for ammonia synthesis, Appl. Catal. A, 300 (2006) 181-185.

[54] P.G. Tsyrul'nikov, K.N. lost, N.B. Shitova, V.L. Temerev, Methanation of the carbon supports of ruthenium ammonia synthesis catalysts: A review, Catal. Ind., 8 (2016) 341-347.

[55] S. Khoobiar, Particle to Particle Migration of Hydrogen Atoms on Platinum-Alumina Catalysts from Particle to Neighboring Particles, J. Phys. Chem., 68 (1964) 411-412.

[56] M. Kitano, Y. Inoue, M. Sasase, K. Kishida, Y. Kobayashi, K. Nishiyama, T. Tada, S. Kawamura, T. Yokoyama, M. Hara, H. Hosono, Self-organized Ruthenium-Barium Core-Shell Nanoparticles on a Mesoporous Calcium Amide Matrix for Efficient Low-Temperature Ammonia Synthesis, Angew. Chem. Int. Ed., 57 (2018) 2648-2652.

[57] Y.V. Larichev, I.P. Prosvirin, D.A. Shlyapin, N.B. Shitova, P.G. Tsyrul'nikov, V.I. Bukhtiyarov, An XPS Study of the Promotion of Ru-Cs/Sibunit Catalysts for Ammonia Synthesis, Kinet. Catal., 46 (2005) 597-602.

[58] M.C. Biesinger, B.P. Payne, A.P. Grosvenor, L.W.M. Lau, A.R. Gerson, R.S.C. Smart, Resolving surface chemical states in XPS analysis of first row transition metals, oxides and hydroxides: Cr, Mn, Fe, Co and Ni, Appl. Surf. Sci., 257 (2011) 2717-2730.

[59] X. Li, Z. Ao, J. Liu, H. Sun, A.I. Rykov, J. Wang, Topotactic Transformation of Metal-Organic Frameworks to Graphene-Encapsulated Transition-Metal Nitrides as Efficient Fenton-like Catalysts, ACS Nano, 10 (2016) 11532-11540.

[60] C.D. Zeinalipour-Yazdi, J.S.J. Hargreaves, C.R.A. Catlow, Low-T Mechanisms of Ammonia Synthesis on $\mathrm{Co}_{3} \mathrm{Mo}_{3} \mathrm{~N}$, J. Phys. Chem. C, 122 (2018) 6078-6082.

[61] W. Arabczyk, U. Narkiewicz, D. Moszynski, Double-Layer Model of the Fused Iron Catalyst for Ammonia Synthesis, Langmuir, 15 (1999) 5785-5789.

[62] R. Jedrzejewski, Z. Lendzion-Bielun, Reduction Process of Iron Catalyst Precursors for Ammonia Synthesis Doped with Lithium Oxide, Catalysts, 8 (2018) 494. 
[63] R. Sawyer, H.W. Nesbitt, R.A. Secco, High resolution X-ray Photoelectron Spectroscopy (XPS) study of $\mathrm{K}_{2} \mathrm{O}-\mathrm{SiO}_{2}$ glasses: Evidence for three types of $\mathrm{O}$ and at least two types of $\mathrm{Si}, \mathrm{J}$. Non-Cryst. Solids, 358 (2012) 290-302.

[64] H.W. Nesbitt, G.M. Bancroft, G.S. Henderson, R. Ho, K.N. Dalby, Y. Huang, Z. Yan, Bridging, non-bridging and free $\left(\mathrm{O}_{2}-\right)$ oxygen in $\mathrm{Na}_{2} \mathrm{O}-\mathrm{SiO}_{2}$ glasses: An X-ray Photoelectron Spectroscopic (XPS) and Nuclear Magnetic Resonance (NMR) study, J. Non-Cryst. Solids, 357 (2011) 170-180.

[65] P.A. van Aken, B. Liebscher, Quantification of ferrous/ferric ratios in minerals: new evaluation schemes of Fe L23electron energy-loss near-edge spectra, Phys. Chem. Miner. 29 (2002) 188200.

[66] D.H. Anjum, W. AlMaksoud, R.K. Rai, B.E. Alsabban, N. Morlanes, J.-M. Basset, Characterization of Catalyst-nanomaterials with Myriad Modalities of Transmission Electron Microscopy, Microsc. Microanal., 25 (2019) 1692-1693.

[67] N.D. Spencer, R.C. Schoonmaker, G.A. Somorjai, Structure sensitivity in the iron singlecrystal catalysed synthesis of ammonia, Nature, 294 (1981) 643-644.

[68] L.M. Falicov, G.A. Somorjai, Correlation between catalytic activity and bonding and coordination number of atoms and molecules on transition metal surfaces: Theory and experimental evidence, Proc. Nat. Acad. Sci. U.S.A., 82 (1985) 2207.

[69] A. Vojvodic, A.J. Medford, F. Studt, F. Abild-Pedersen, T.S. Khan, T. Bligaard, J.K. Nørskov, Exploring the limits: A low-pressure, low-temperature Haber-Bosch process, Chem. Phys. Lett., 598 (2014) 108-112.

[70] H. Fan, X. Huang, K. Kähler, J. Folke, F. Girgsdies, D. Teschner, Y. Ding, K. Hermann, R. Schlögl, E. Frei, In-Situ Formation of Fe Nanoparticles from FeOOH Nanosheets on y-Al2O3 as Efficient Catalysts for Ammonia Synthesis, ACS Sustain. Chem. Eng., 5 (2017) 10900-10909.

[71] C. Liang, Z. Wei, M. Luo, P. Ying, Q. Xin, C. Li, Hydrogen Spillover Effect in the Reduction of Barium Nitrate of Ru-Ba( $\left(\mathrm{NO}_{3}\right)_{2} / \mathrm{AC}$ Catalysts for Ammonia Synthesis, in: A. Guerrero-Ruiz, I. Rodríguez-Ramos (Eds.) Studies in Surface Science and Catalysis, Elsevier, 2001, pp. 283-290.

[72] J.J. Mortensen, L.B. Hansen, B. Hammer, J.K. Nørskov, Nitrogen Adsorption and Dissociation on Fe(111), J. Catal., 182 (1999) 479-488.

[73] C.J.M. van der Ham, M.T.M. Koper, D.G.H. Hetterscheid, Challenges in reduction of dinitrogen by proton and electron transfer, Chem. Soc. Rev., 43 (2014) 5183-5191.

[74] A.L. Garden, E. Skúlason, The Mechanism of Industrial Ammonia Synthesis Revisited: Calculations of the Role of the Associative Mechanism, J. Phys. Chem. C, 119 (2015) 2655426559. 


\section{Conflict of interest}

The authors declare no conflict of interests. 